Portland State University

PDXScholar

\title{
Monitoring and management of psychiatric symptomatology in conditionally released insanity acquittees
}

Jo Mariah Mahler

Portland State University

Follow this and additional works at: https://pdxscholar.library.pdx.edu/open_access_etds

Part of the Counseling Commons, and the Education Commons Let us know how access to this document benefits you.

Recommended Citation

Mahler, Jo Mariah, "Monitoring and management of psychiatric symptomatology in conditionally released insanity acquittees" (1992). Dissertations and Theses. Paper 4331.

https://doi.org/10.15760/etd.6215

This Thesis is brought to you for free and open access. It has been accepted for inclusion in Dissertations and Theses by an authorized administrator of PDXScholar. Please contact us if we can make this document more accessible: pdxscholar@pdx.edu. 
AN ABSTRACT OF THE THESIS OF Jo Mariah Mahler for the Master of Science in Education: Counseling presented July 9, 1992.

Title: Monitoring and Management of Psychiatric Symptomatology in Conditionally Released Insanity Acquittees.

APPROVED BY THE MEMBERS OF THE THESIS COMMITTEE:

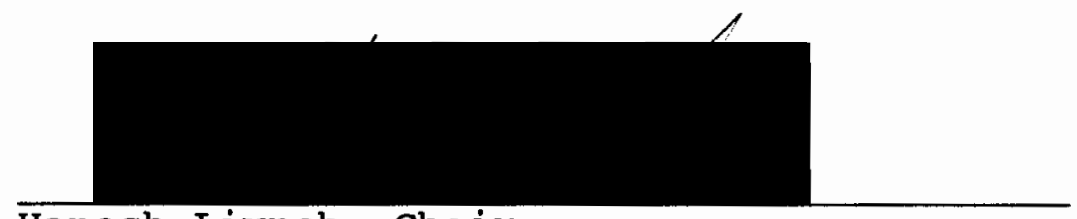

Hanoch Livneh, Chair
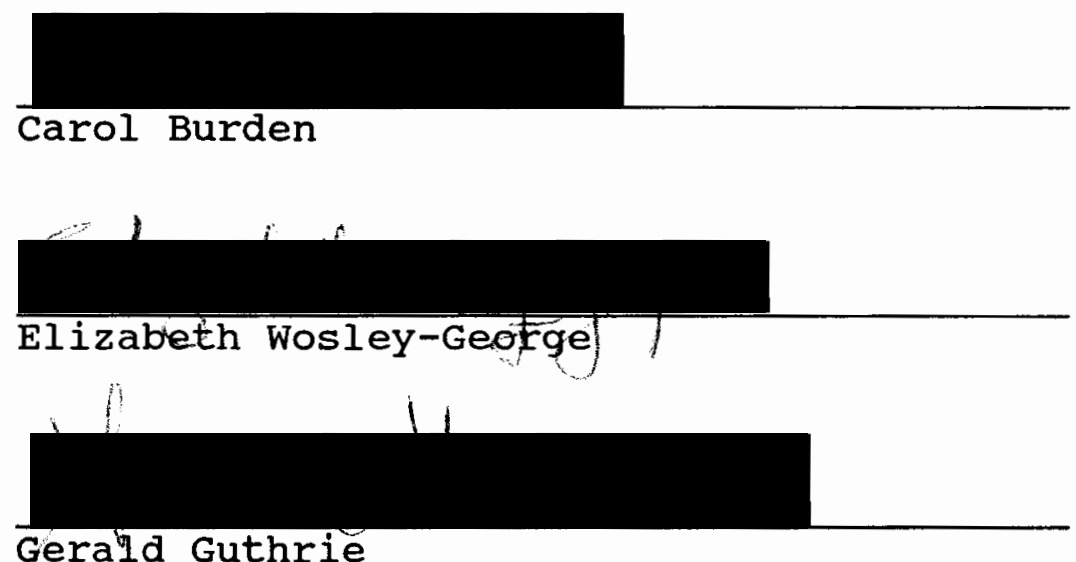

Community treatment of insanity acquittees is a highly controversial matter among legislators, mental health professionals and the public. At issue is the balancing of public safety concerns with least restrictive, non-punitive rehabilitation alternatives for insanity acquittees. Attempts to determine predictors of dangerousness in 
mentally ill offenders have produced mixed results with questionable practical value. In view of this, many mental health professionals are instead recommending that research on insanity acquittees be focused on evaluating the effectiveness of mandated community treatment programs for insanity acquittees. One area being designated for such research is the monitoring and management of psychopathology in conditionally released insanity acquittees, as mental deterioration in this population is a primary concern in assuring public safety. This thesis examined the monitoring and management of psychiatric symptomatology in a subsample of conditionally released insanity acquittees.

The data for this thesis were extracted from an existing database belonging to the Psychiatry Department at oregon Health Sciences University (OHSU). This database contained information from interviews conducted between August 1, 1987 and July 31, 1989 with 54 male psychotic felons on conditional release during this period to closely monitored community treatment programs in oregon. Additional data in this database had been derived from interviews with these subjects' case managers. Data were in the form of (1) computer data files; (2) computerized printouts of summary reports for frequencies, means and standard deviations; and (3) raw data.

This author analyzed scores from the subject-rated Symptom Checklist 90, Revised version (SCL-90-R) and the 
interviewer-rated Global Assessment Scale (GAS) from the Schedule for Affective Disorders and Schizophrenia--Change (SADS-C) to determine the degree of symptomatic distress and level of overall functioning of these subjects. In addition, case manager interview data on subjects' mental condition, treatment compliance, legal contacts or charges, dangerousness, and reasons for rehospitalization were reported.

Results from statistical analyses of the SCL-90-R and GAS scores indicated less reported distress from psychiatric symptomatology and better overall functioning than expected for psychiatric outpatients. The overall mean for all scores on the Global Symptom Index (GSI) of the SCL-90-R was highly significant, falling more than one standard deviation below the expected mean. The overall mean for all scores on the GAS was 61.4 , indicating a fairly high level of functioning for this population. Improvement over time in GAS and GSI scores between first and last interviews was statistically significant for a subsample of subjects who had scores for all interviews.

Examination of case manager data on subjects' compliance and mental condition revealed few reported problems for significant or extreme severity ratings. of the seven subjects for whom reports of dangerousness were rated as significantly or extremely problematic, none required rehospitalization during the study period. Case 
managers reported a total of eight incidences of legal contacts or charges. Charges were filed in two of these cases, but neither re-offenses were as serious as the crimes for which the subjects were originally acquitted.

Case managers cited alcohol and drug use as a primary reason for rehospitalizing six of the sixteen rehospitalized subjects and as the most common treatment plan violation. Case managers stated that mental decompensation was a primary reason for rehospitalization in only three of the subjects. 
MONITORING AND MANAGEMENT OF PSYCHIATRIC SYMPTOMATOLOGY

IN CONDITIONALLY RELEASED INSANITY ACQUITTEES

by

JO MARIAH MAHLER

A thesis submitted in partial fulfillment of the requirements for the degree of

MASTER OF SCIENCE

in

EDUCATION : COUNSELING

Portland State University

1992 
TO THE OFFICE OF GRADUATE STUDIES:

The members of the committee approve the thesis of Jo Mariah Mahler presented July 9, 1992 .

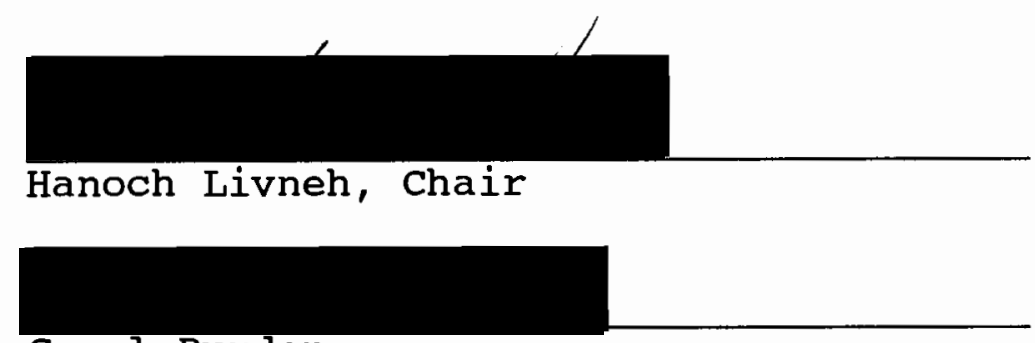

\section{Carol Burden}

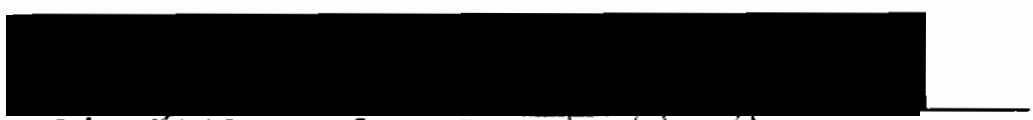

Elizabeth wosley-George d

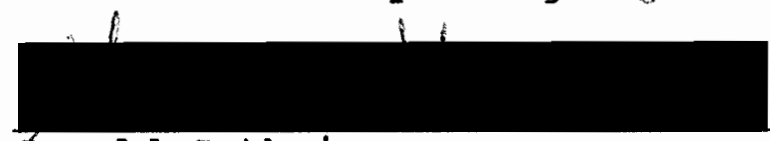

Gerald Guthrie

APPROVED :

Robert B. Everhart, Dean, School of Education C. William Savery, Vice Provgst for Graduate studies
and Research 


\section{ACKNOWLEDGEMENTS}

I wish to express my appreciation to the organizations and many individuals who have supported the development of this thesis. To the following members of the Department of Psychiatry and the Western Mental Health Research center (the writing of this thesis was partially supported by NIMH grant P50-MH43458) at Oregon Health Sciences University (OHSU) : Dr. Joseph Bloom, Mary Williams, Dr. Bentson MCFarland, and Dr. Greg Clarke. Thank you for your personal and professional support and encouragement, and valuable editorial advice. Your continuing dedication to mental health research on topics of critical concern for mental health care consumers, clinicians, and policy makers deserves the highest praise.

To Dr. Barbara stewart from the School of Nursing at OHSU. I truly appreciate your kindly help in the initial stages of my data analysis. You unhesitatingly donated support and advice without any expectation of reward. Thanks for your unselfish contribution.

To Hanoch Livneh, my Thesis Committee Chair. Thank you for a writing and research professionalism that encouraged me to strive for excellence. Your sense of humor and professional wisdom were delightful contributions in our lively discussions. I always left our thesis meetings 
feeling encouraged and supported.

To Carol Burden, Committee member and my Counseling Education program advisor. Your faith in my ability to succeed, and your willing efforts to ensure that I would, will not be forgotten. I could always count on you to readily discern and clarify for me the fundamental issues of any concern I brought to you. Carol, thank you for being there these past three years.

To Elizabeth Wosley-George, Committee member and my Practicuum advisor. Thank you for showing so much personal interest in my professional growth and development, as well as for sharing with me your invaluable professional insights about the topic of this thesis. I am especially appreciative of your warm encouragement to trust my instincts and abilities to know what works best.

And finally, many thanks to my family and friends who continued to tell me, "you can do it." In particular, to Ardie sherwood. Your willingness to share, with great empathy and unmatched humor, your own past experiences with "the thesis" process, helped me persevere through my own frustrations and fears. I am exceedingly grateful for your friendship. 
TABLE OF CONTENTS

PAGE

ACKNOWLEDGEMENTS • • • . • . . . . . . . . . . . iii

LIST OF TABLES . . . . . . . . . . . . . . . . vii vi

LIST OF FIGURES . . . . . . . . . . . . . . . . viii

CHAPTER

I INTRODUCTION AND PROBLEM STATEMENT • • • • . 1

Deinstitutionalization. . . . . . . 3

Insanity Defense. . . . . . . . 6

Oregon's PSRB System. • . • . . . . 9

Mental Illness and Dangerousness. . . 12

II LITERATURE REVIEW. • . . . . . . . . . 18

III METHODOLOGY. . . . . . . . . . . . 24

subjects. . . . . . . . . . 24

Instruments . . . . . . . . 25

Procedure . . . . . . . . . 29

Calculations. . . . . . . . . 34

IV PRESENTATION AND ANALYSIS OF THE DATA. . . . 39

Demographics. . . . . . . . . . 39

SCL-90-R Results . . . . . . . . 44

Nine Symptom Dimensions

GSI

GAS Results . . . . . . . . . . 
Case Managers' Reports of Problems. .

Compliance with Treatment Mental/Emotional Condition Dangerousness

Legal Contacts/Charges

Reasons for Rehospitalization

V

DISCUSSION AND RECOMMENDATIONS • . . • • •

59

Summary of Findings and Conclusions.

Substance Use

Limitations of the study. . . . . . .

Recommendations for Further Research. 


\section{LIST OF TABLES}

TABLE

PAGE

I Demographic Characteristics . . . . . .

II Lifetime Number of Psychiatric Hospitalizations as Reported by subjects. . . . .

III Primary Psychiatric Diagnosis Around Time of Assignment to PSRB . . . . . . . . . . 42

IV Type of crime for which Subject Was Acquitted in order of Most to Least Serious. . .

V All Means For 9 Symptom Dimensions of the SCL-90-R . . . . . . . . . . . 44

VI t-Test Results For the Nine Symptom Dimensions of the SCL-90-R For 13 subjects With All Scores For $\mathrm{T}_{3}-\mathrm{T}_{8}$. . . . . . 45

VII All Means Calculated for GSI . . . . . . 47

VIII All Means Calculated for GAS. . . . . . 50

IX Frequency of Incidences of Dangerousness Reported by Case Managers . . . . . . 


\section{LIST OF FIGURES}

FIGURE

PAGE

1. Subject Movement Patterns During Study

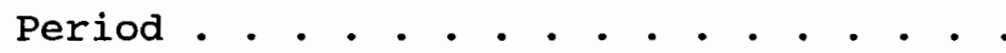


Generally it is relatively easy to accomplish the goal of security; to also achieve the goals of humane care and treatment is much more problematic. There is a well developed technology to build and maintain secure facilities. Reforms that have as their goals increased security and longer detention for any class of persons in the criminal justice or mental health systems have very good chances of success. Money can buy security. Often, however, that security is unnecessary... Without more clinical research on the insanity acquittee, there is little chance that innovative reforms responsive to their treatment needs will be forthcoming. The technology for psychiatric treatment is much more complex and less predictable than that for security. As a result, it is much easier to assuage public fears of NGRIs [those individuals found Not Guilty by Reasons of Insanity] by reforms predicated on increased security that may perpetuate inadequate treatment environments than to assuage these fears by reforms offering innovative treatment programs. 
CHAPTER I

\section{INTRODUCTION AND PROBLEM STATEMENT}

Mandated community-based care and management of insanity acquittees--those criminal offenders who successfully plead insanity for their crimes--has received little attention in research and practice. Most states choose to hospitalize insanity acquittees, the majority of whom have been diagnosed with psychoses, particularly schizophrenia, and have histories of contacts with criminal justice and mental health systems (Bloom, Bradford, \& Kofoed, 1988; Bloom, Williams, Rogers, \& Barbur, 1986; Golding, Eaves, \& Kowaz, 1989; Kumjukrishnan \& Bradford, 1988; Lamb, Weinberger, \& Gross, 1988a,b; Leong, Silva, \& Weinstock, 1991; Steadman, 1985; Zonana, Wells, Getz, \& Buchanan, 1990). Although some research on alternatives to hospitalization for mentally ill offenders has been undertaken, according to Phillips, Wolf, and Coons (1988), "methods of managing mentally ill offenders are in such a state of flux" (p. 608) that it is difficult to compare research findings between jurisdictions. These authors add that despite this difficulty, "the problems faced in trying to manage mentally ill offenders are similar across jurisdictions, and so methods developed to identify and 
analyze such problems" (p. 608) in one jurisdiction are helpful to others serving this population. One predominant problem in community aftercare for this population is the control of psychiatric symptoms.

Insanity acquittees represent the interface of two systems--the mental health system and the criminal justice system. An overview of these systems' histories reveals how each has contributed to the current lack of noninstitutionalized treatment alternatives for insanity acquittees in most jurisdictions. This introduction will present recent highlights of these histories which have affected the current care and management of insanity acquittees. Against this backdrop, I will then examine the principal interest of this thesis--the ability to manage and monitor insanity acquittees' psychiatric symptomatology during mandated community treatment, as assessed by mental health status outcome measures, and case managers' reports of conditionally released acquittees' functioning and mental health condition.

A history of the mental health system is presented here first, and focuses on deinstitutionalization--the aggressive and ubiquitous release of psychiatric patients from hospitals into the community. This will be followed by an overview of historical features of the criminal justice system that have influenced the insanity defense and disposition of insanity acquittees. 


\section{DEINSTITUTIONALIZATION}

Mental health systems throughout the U.S. instituted large-scale deinstitutionalization of mentally ill patients from psychiatric hospitals beginning in the early 1960s, and continuing into the mid- to late '70s. Some deinstitutionalization had begun in the mid- to late '50s, but it was not until the introduction of federal community Mental Health Center legislation in 1963 that the decision to release psychiatric inpatients became so widespread. Federal intervention into this area was a result of growing dissatisfaction with what was viewed as ineffectual and unethical treatment of the mentally ill (Rose \& Black, 1985). Prior to this legislation, which provided federal funds for psychiatric outpatient services, state and county governments assumed responsibility for administering mental health services. These non-federal bodies dispensed mental health services chiefly through inpatient psychiatric facilities.

The major goal of deinstitutionalization--reducing the inpatient psychiatric population--was, at least on the surface, initially successful. Rose and Black (1985) cited a report from the Comptroller General, dated 1977, that stated that the number of public mental hospital inpatients was reduced from 559,000 in 1955 to approximately 215,000 in 1974, a 57\% decrease (p. 4). Unfortunately, another aim of federal deinstitutionalization legislation--community 
aftercare for discharged patients--was not so painstakingly pursued. Community services for these patients were unduly deficient, the result of an inadequate response by state and local mental health agencies to fund and otherwise support aftercare services to discharged patients. Patients were sent from the secure, although therapeutically inadequate, structure of the hospital into unfamiliar, unresponsive, and stressful community environments without benefit of transitional and maintenance support services. Prior to 1975, the majority of deinstitutionalized psychiatric patients were abandoned to nursing homes; for many of the remaining patients, variations of "for profit" room and board facilities provided food and shelter, but little else (Rose \& Black, 1985).

In time, rehospitalization (recidivism) rates began to rise. State legislative reports from New York, representative of recidivism activity in other states, indicated that in New York state "readmissions to state facilities [rose] from 12,514 in 1965 to 21,591" in 1975 . In addition, "17,501 people were readmitted to New York state psychiatric hospitals between April 1974 and March 1975," and "by 1975, over 63 per cent of all admissions to mental hospitals in New York were readmissions" (Rose \& Black, 1985, p. 5). This movement of psychiatric patients between hospital and community care became known as "the revolving door" syndrome (Bursten, 1986; Rose \& Black, 1985; 
Seling \& Johnson, 1990). The parsimonious expenditures earmarked for Community Mental Health Centers were absorbed by the costs of increased inpatient care, which only further exacerbated the insufficiencies of community aftercare.

Beginning in 1975, public and professional discontent with the inadequate response of state mental health systems to the needs of revolving door patients initiated reform measures. Several amendments and judicial decisions on the national level began to address the need for more and better community mental health services. The National Institute of Mental Health (NIMH) funded pilot projects with several state mental health agencies that were to enhance their community services and promote more comprehensive planning of aftercare services. These agencies, community support systems (CSSs), were expected to provide outpatient care that went far beyond medication maintenance and basic food and shelter, to include income supports, training and employment considerations, socialization needs, client advocacy for obtaining services, and crisis care (Rose \& Black, 1985). As pressure increased on state and local governments to rectify the disturbing results of deinstitutionalization, many states sought to restructure their own community mental health delivery systems with a new emphasis on case management and comprehensive service provision. 


\section{INSANITY DEFENSE}

The disposition of one subgroup of psychiatric patients that remained highly controversial during deinstitutionalization was that of insanity acquittees. An inquiry into the criminal justice system's involvement with the insanity defense provides a framework for understanding the nature of this controversy. Up until the mid-twentieth century, the insanity defense in the United States was based on the M'Naghten rule of 1843 from England, which stated that a person "is not responsible for his criminal acts when, because of a 'disease of the mind,' he does not know the 'nature and quality' of his acts or does not know they are 'wrong'" (Caplan, 1984, p. 20). Under this rule, a person who the court believed to be insane at the time of his crime could still be convicted if he knew at the time he committed the offense that it was wrong. Many insane criminals were subjected to imprisonment or the death penalty. Those who were acquitted, who were found not to know right from wrong, were commited to long-term psychiatric hospitalization, many without opportunity for later review of their mental condition.

In the mid-twentieth century a new standard for the insanity defense was established in the United states. In 1954 the District of Columbia Court of Appeals determined that a person who knew right from wrong, but who lacked "emotional appreciation that what he did was wrong" or 
lacked "control because of his derangement" (Caplan, 1984, p. 22), deserved acquittal. This decision, known as the Durham rule, extended the use of the insanity defense but did not end the controversy. To this day, professionals from a variety of disciplines and the general public itself continue to deliberate what constitutes a valid insanity defense and post-defense disposition.

The Durham ruling was followed by legal and clinical advances that improved the care and management of insanity acquittees. Spurred on by Durham, legal reforms that accorded insanity acquittees more civil rights were enacted. One of the most important of these was the right to periodic post-insanity defense hearings to determine if an acquittee continued to be mentally ill and/or dangerous (Caplan, 1984). Another result of deinstitutionalization legislation was that insanity defense systems in many states became more inclined to process insanity acquittees through civil commitment (involuntary hospitalization) proceedings rather than in the criminal courts (Bloom \& Bloom, 1981). The idea of punishing an insane person for her or his mental illness-as imprisonment implied--was objectionable in this era of empathy towards the mentally incapacitated.

In addition to these specific legal actions which benefitted insanity acquittees, changes in the treatment of psychiatric disorders also influenced legislative activity. Psychiatry began seriously to question the therapeutic 
effectiveness and ethics of long-term hospitalization. New forms of chemotherapy that controlled psychiatric symptoms-and in turn, held the potential to reduce dangerousness-allowed psychiatrists and legislators to consider the option of community mental health care in the mid-i70s (Caplan, $1984)$.

Such generosity towards the disposition of insanity acquittees was not to last, however. By the late 1970s, public and professional sentiment about the lack of consequences for post-insanity defense cases, increasing numbers of insanity defenses, and growing concern for public safety arising from a few highly publicized crimes by released acquittees, led many states to re-evaluate and alter legislation which had favored insanity acquittees (Bloom \& Bloom, 1981; Morgan, McCullough, Jenkins, \& White, 1988). Although some of these changes were made prior to the "not guilty by reason of insanity" verdict in John Hinckley's assassination attempt on President Reagan in 1982, the Hinckley case fueled the public's and politicians' desire to emphasize more strongly public safety over the rehabilitation of mentally ill offenders (Golding et al., 1989; Morgan et al., 1988; Spodak, Silver, \& Wright, 1984). Changes in legislation reflecting the above attitude included limiting the use of the insanity defense, decreasing the restrictions on civil commitment criteria (Harry \& Steadman, 1988), and imposing tighter dispositional 
controls (Leong et al., 1991; Nelson \& Berger, 1988). In Maryland, for example, a mandatory five-year conditional release to monitored community programs is required of all discharged insanity acquittees (Lamb et al., 1988a). Colorado passed legislation requiring acquittees to be hospitalized before being considered for community treatment (Schutte, Malouff, Lucore, \& Shern, 1988). Montana, Idaho, and Utah restricted the insanity defense to the M'Naghten ruling, excluding from the defense those who are found to know right from wrong, no matter what reasons they believed they had for committing the offense (Caplan, 1984). In California, "few physically violent individuals are returned to the community" prior to serving the maximum possible commitment time (Leong et al., 1991, p. 212). These are only some examples of the post-deinstitutionalization legislative changes that have resulted in tighter control around insanity acquittees and their defense.

\section{OREGON'S PSRB SYSTEM}

Oregon's response to the late '70s revisionist legislation was the 1977 creation of the Psychiatric Security Review Board (PSRB), a 5-member Board which maintains jurisdiction over all insanity acquittees in the state. This was a unique response to the conflicting concerns of the public's demands for more safety and mental health professionals' desire to rehabilitate. The Board is 
comprised of a psychiatrist, a psychologist, a lawyer, a person familiar with parole and probation, and a lay citizen.

Once a trial court determines that a person was insane at the time his or her crime was committed and that the defendant is still mentally ill and dangerous, the defendant is assigned to the jurisdiction of the PSRB for the length of time equal to the maximum sentence the person could have received had he or she been found guilty of the offense. The judge then determines the initial disposition of the acquittee, which can be hospitalization, conditional release to the community, or discharge from the Board's jurisdiction. From this point on, any acquittee who was not discharged by the Board is under the sole control of the PSRB until the Board discharges the acquittee or the jurisdiction time elapses. Until discharged, the Board determines the acquittee's disposition. Conditional release of a PSRB client is based on her or his stability and readiness for community placement and by the availability of appropriate programs. The Board holds periodic hearings to determine whether or not to conditionally release a client. The county district attorney, representing the state, the client's attorney, and independent clinicians may offer testimony as to the wisdom of releasing a client to the community. A proposed conditional release plan is presented to the Board, which, upon hearing the testimony and the 
contents of the plan, then decides either to deny or grant a conditional release or to require changes in the plan before granting a release (Bloom, Rogers, \& Manson, 1982; Bloom, Williams, \& Bigelow, 1991; Rogers \& Bloom, 1985).

The Board must provide as its primary goal the protection of society from dangerous mentally ill persons. It is also a concern of the PSRB that treatment of the acquittee be provided in the least restrictive placement, in which public safety can be maintained while not violating the right of the client to a non-punitive, rehabilitative environment. In writing about the need for alternatives to hospitalization for oregon's insanity acquittees, Rogers and Bloom (1985) stated that:

it is disingenuous to assert that involuntary hospitalization does not have punitive elements... In evaluating the claim that prison is punishment and hospitalization is not, one should compare the maximum security ward of the hospital with the psychiatric ward of the prison. In oregon, at least, they are only blocks apart and are strikingly similar in physical appearance and to some extent in program. Confinement, after an insanity verdict, may not be intended as punishment, but in part is. (p. 77)

Under Oregon's PSRB system, conditions for release of an acquittee allow clients who are still mentally ill and potentially dangerous to live in monitored community settings (Rogers \& Bloom, 1985), reducing the punitive components of confinement. 


\section{MENTAL ILINESS AND DANGEROUSNESS}

The two major client-related issues surrounding the disposition of insanity acquittees--mental illness and dangerousness--must be adequately controlled when an acquittee is released into the community, from both a public safety and a rehabilitation standpoint. The ability to predict dangerousness reliably understandably holds great appeal, for if that were possible, then ensuring public safety would be simplified. As it stands, many studies focusing on predicting dangerousness in formerly dangerous and potentially dangerous insanity acquittees have been conducted with unsuccessful results (Prins, 1990). Quinsey (1988) surveyed the literature related to predicting dangerousness and recidivism in insanity acquittees. Referring to approximately 25 publications, Quinsey reported that the majority of these articles make no attempt to predict dangerousness using "measures of therapeutic change" (p. 446). Of those studies which reported on reliable predictor variables, the studies' researchers found that such factors are "static variables such as offense history, I.Q., and diagnosis" (p. 446). Although these variables can help prepare mental health workers for potential treatment concerns, the above immutable variables provide no information about factors that can be influenced to decrease dangerousness and what forms of treatment have the greatest influence on them. 
In addition to the above findings, research has also indicated that dangerousness in insanity acquittees may not be as serious a problem as the public fears. In reviewing studies of insanity acquittee outpatients from Illinois, Maryland, and Oregon, Lamb et al. (1988a) reported that during court-mandated community care of these clients, criminal justice contacts occurred infrequently and typically were for minor offenses. Phillips et al. (1988), in interviews with clinicians and officials familiar with Connecticut's PSRB, reported that "several respondents observed that while insanity acquittees are severely impaired, most function at a higher level than nonadjudicated psychiatric inpatients" (p. 984).

In another study, Spodak et al. (1984) found that despite "very serious original charges, insanity acquittees as a group do not present a substantial danger to public safety when discharged from the hospital" to carefully supervised aftercare, and that "the period of greatest risk for criminal recidivism in this population" (p.382) is in the first five years of community aftercare. Cavanaugh and Wasyliw (1985b) echoed this viewpoint by stating that "a carefully administered and closely supervised outpatient treatment program for NGRI patients may be a viable and preferable alternative either to prolonged institutionalization or to unconditional, unsupervised discharge" (p. 415). According to these authors' research 
findings, "outpatient treatment was associated with stability or improvement in psychologic functioning in a manner consistent with public safety concerns" (p. 415). Aadland and Schag (1984) and Cohen, Spodak, Silver, and Williams (1988) also agreed with the findings that predicting future dangerousness in mentally ill offenders is fraught with problems and that dangerousness itself has been overpredicted.

Continuing in this vein, a study of patients having first-time psychiatric contact in outpatient, inpatient, or emergency services at a community mental health clinic in Missouri was conducted by Harry and steadman (1988). These authors found that over a ten-year period, comparing arrest rates with the general population, there were fewer postadmission arrests for these three groups of patients (inpatient, outpatient, and emergency) together than postadmission arrest rates for subjects in studies restricted to inpatients. Thus, the inclusion of non-hospitalized patients (outpatient and emergency patients) in Harry and Steadman's study of mentally ill offenders did not increase post-admission arrest rate findings; rather, such arrest rates were less than for studies which omitted the outpatient subgroups in their samples.

Indeed, this inability to reliably predict dangerousness has led mental health professionals, including many of those discussed above, to recommend a refocusing of 
research activities related to dangerous mentally ill people. These clinicians and researchers have suggested that energy and resources should instead be spent on evaluating the effectiveness of mandated community mental health programs in a variety of areas. Some of the areas being designated for further research include the importance of close supervision and monitoring of clients in controlling dangerousness and mental deterioration; determining types of social and economic services that improve clients' quality of life; discovering the degree of, and problems associated with, client substance abuse; identifying the specific reasons for clients' rehospitalization; and measuring the cost-effectiveness of community care (Bloom et al., 1991; Cavanaugh \& Wasyliw, 1985a,b; Eisner, 1989; Golding et al., 1989; Goldmeier, White, Ulrich, \& Klein, 1980; Kumjukrishnan \& Bradford, 1988; Lamb et al., 1988a; Leong et al., 1991; Nelson \& Berger, 1988; Schutte et al., 1988; Steadman, 1985).

Mental deterioration is among the most significant reasons for deciding to rehospitalize insanity acquittees, particularly when it is felt that mental decompensation is increasing an acquittee's dangerousness (Aadland \& Schag, 1984; Cavanaugh \& Wasyliw, 1985a,b; Cohen et al., 1988; Golding et al., 1989; Goldmeier et al., 1980; Rogers \& Bloom, 1985). Golding et al. (1989) argued for an approach to community mental health care that recognizes and 
signifies severe psychopathology, rather than criminality, as the most important contributing factor in aggressive behavior of mentally ill clients. These authors stated that monies should be re-allocated to "aspects of the forensic mental health delivery system that targets severely mentally disordered individuals with the kinds of delusions, hallucinations, and other problems that significantly raise the probability of their offending aggressively as a function of their mental disorder" (p. 177). Although these authors' central concern was advocating for assertive management of dangerous psychopathology of mentally ill clients prior to their committing illegal acts that might lead to involvement with the criminal justice system, it can be surmised that a similar emphasis on monitoring symptomatology in current conditionally released insanity acquittees to avoid decompensation and return to pre-release levels of functioning, and by implication, to avert dangerous acts would also be strongly recommended.

Staff members, including residential workers and case managers, who work directly with released mentally ill offenders, are typically the ones to assess the need for rehospitalization of clients. Goldmeier et al. (1980) in writing about the structure of a community residential program for mentally ill offenders, stated that signs of recurring mental illness in residents was a prominent signal that halfway house staff employed, in conjunction with 
difficulties clients were experiencing in their social situations (work, residence, family), to alert staff to potentially dangerous behavior. The authors recommended the continual assessment of personality changes along with close monitoring of "social situations that could potentially stimulate aggression" (p. 73) in their clients.

Given the views expressed by these researchers, monitoring of conditionally released insanity acquittees' mental condition appears to be an immensely important ingredient in balancing the concern for public safety with rehabilitation. This thesis examines the management of psychiatric symptomatology of a subsample of insanity acquittees on conditional release in closely monitored community treatment programs in oregon. 
CHAPTER II

\section{LITERATURE REVIEW}

The importance of monitoring mental symptomatology in mentally ill clients living in the community has been the focus of several researchers. Avison and speechley (1987) summarized findings of 133 studies published between 1973 and 1984, inclusively, on the adjustment to community living of psychiatric patients discharged from full-time psychiatric facilities. Several assumptions were reported to be operating in the research findings examined. In summary, these authors stated that community care is preferable to hospitalization for psychiatric patients. They recommended that community treatment for such discharged patients provide opportunities for leading productive, active, and socially engaged lives that are not overly stressful, and that others' expectations of patients are ones to which patients can successfully conform.

These authors stated that these assumptions point to multiple factors as measures of predictability in adjustment to community living, such as role performance, social relationships, and meaningful use of time. They suggested that instruments that take into account more global factors in their ratings of adjustment would be more valid than 
those which focus primarily on one or two factors. One of the instruments these authors recommended to rate adjustment is the Global Assessment scale (GAS) from the Schedule for Affective Disorders and Schizophrenia--Change (SADS-C).

In a study which examined the community adjustment of severely mentally ill subjects, Baker and Douglas (1990) considered the importance of providing appropriate residential environments for such adjustment. One of the measures used to determine the quality and appropriateness of residences was the GAS. A significant relationship was reported between residential adequacy and subjects' adjustment, in that subjects living in appropriate housing had better GAS ratings, while the mental health of those who resided in inappropriate settings deteriorated significantly.

In Aadland and Schag's (1984) study of mentally ill sex offenders living in a mandated outpatient treatment program, these authors found that judgments made by staff as to when to release a client from the program were most often based on clinical assessments of mental status, not on static variables like demographics or criminal history. These authors concluded that mental health status is the main criterion used by clinicians to determine clients' potential threat to the community.

Two studies from the state of Maryland, which has a mandatory 5-year conditional release for insanity acquittees 
discharged from inpatient care, reported on subjects' adjustment to community care. Goldmeier et al. (1980) examined recidivism rates (both rearrests and rehospitalizations) of subjects conditionally released to a halfway house in Baltimore. Most subjects were paranoid schizophrenic and had histories of dangerousness. In followup studies over nearly a 2-year period, 40.5\% were rehospitalized, some to avert the occurrence of dangerous behaviors. Only $15 \%$ committed new offenses, which were less serious than the original offense. One of the signals used to alert staff to potential problems was signs of mental deterioration. Timely rehospitalization was viewed as a positive option for preventing re-offending. The authors stated that "the staff was mindful of the fallacy...that hospitalization per se is bad for patients" (p. 77). The authors stressed that changes in mental status require ongoing assessment in conjunction with close monitoring of the environment for mentally ill offenders in residential care.

In a second Maryland study, Cohen et al. (1988) studied 127 male insanity acquittees released from psychiatric hospitalization in Maryland between January 1, 1967 and December 31, 1978. All of these subjects had felony charges, had been released under the mandatory five-year conditional release program, and had spent from 7 to 17 years in the community after the mandatory release time had 
expired. A matched control group of convicted felons and a comparison group of prisoners transferred to psychiatric care who were subsequently transferred back to prison and later placed on parole were also studied. Outcome indicators included rearrest and rehospitalization data, GAS and scores for neurotic and psychotic symptoms based on mental evaluations given just prior to release, and two and a half and five years after release. For the acquittee group, GAS scores at discharge were significantly associated with subjects' post-release functioning. Over threequarters of subjects with low GAS scores had poor functioning after release. On the other hand, only $42 \%$ of subjects with high GAS scores had post-release functioning rated as poor. The best functioning post-release subjects from the study included those who scored 50 or better on the GAS at time of release.

A two-year study of the functioning of court-mandated outpatients in chicago also evaluated the psychological adjustment of insanity acquittees. Cavanaugh and wasyliw $(1985 a, b)$ demonstrated a pattern of improvement over time in these client's mental health adjustment. The authors used the SADS-C and the Symptom Checklist 90, Revised Version (SCL-90-R) at 4-month intervals the first year and 3-month intervals the second year (for a total of five administrations). There was significant improvement in two of the SADS-C subscales--depression and loss of interest. 
All measures of this instrument showed decreased psychopathology over time. Obsessive-compulsive and depressive symptomatology, as measured by the SCL-90-R subscales, also showed significant improvement. Symptoms for all of the other subscales from the SCL-90-R also showed decreases, although not statistically significant ones. The above authors reported that $25 \%$ of the subjects were rehospitalized over the study period. There were no arrests for violent crimes or for crimes against persons. The authors stated that improved GAS scores were chiefly attributable to subjects' increased insight into their mental disorder, symptoms, warning signs, and need for medication.

In summary, the researchers cited in this review appear to value the monitoring of mental symptomatology in insanity acquittees being treated in the community. Cavanaugh and Wasyliw $(1985 a, b)$ agreed with these researchers. These authors concluded that "close monitoring [through adjustment ratings of the GAS and SCL-90] allowed for timely rehospitalization which had the intent of preventing or alleviating those psychopathological or environmental conditions under which prior violent or other criminal acts occurred" (1985a, p. 29). They stated that when mental decompensation occurs rehospitalization is seen as "an appropriate strategy for maintaining NGRI [Not Guilty by Reasons of Insanity] patients in the community" (1985b, p. 
413), and that this "group of patients predominantly characterized by past dangerous behavior and major mental disorder, can be managed safely and stably in the community" (1985a, p.29). 
CHAPTER III

METHODOLOGY

SUBJECTS

Sixty-two subjects conditionally released to oregon's three largest community mental health treatment programs were eligible for this interview study between August 1, 1987 and July 31, 1989. The subjects were under the jurisdiction of the Psychiatric Security Review Board, having been found guilty except for insanity (Oregon Revised Statutes, $\$ 161.319$ (1), 1990) following the commission of a felony or felonies. The sample was limited to male psychotic felons. Only subjects who met the research criterion for a psychotic diagnosis were included. This criterion required subjects to have had at least half of their prior diagnoses (as recorded in psychiatric hospitalization records) to be some type of psychosis. Some subjects were not given a psychotic diagnosis at the time they came under the jurisdiction of the PSRB, yet if they had a history of psychosis based on the above criteria, researchers included them in the study sample.

Female acquittees were excluded from the sample for several reasons. Females represent only about $11 \%$ of oregon's insanity acquittee population, commit significantly 
fewer and different types of felonies than men $(58 \%$ of female insanity acquittees committed felonies, compared to $75 \%$ of male insanity acquittees), and females are treated differently than male clients under the PSRB (i.e., women are hospitalized for shorter periods of time, discharged from the Board at higher rates, and are perceived as less threatening) (Rogers, Sack, Bloom, \& Manson, 1983). Due to these differences the researchers felt that responses from female subjects would require separate analyses from that of male subjects. Furthermore, researchers believed that the number of potential female subjects was inadequate to produce a representative sample of female acquittees. of the sixty-two eligible subjects, seven refused to participate at all in the study and one was not available due to employment conflicts. A total of 54 subjects actually participated in the interviews.

\section{INSTRUMENTS}

The research team developed several instruments specifically designed to learn more about the subjects' background and their experiences in community life under carefully supervised and monitored care. Subjects provided demographic information via a client background questionnaire. Case managers reported, in response to a structured case manager interview questionnaire, on the severity of problems with subjects' treatment compliance, 
mental or emotional condition, and perceived dangerousness. Case managers rated clients' problems in the above areas on a three-point scale of "no or minor problems," "significant problems," or "extreme problems." Case managers also described any legal contacts or charges clients experienced, as well as violations of their treatment plans. Ratings for the case manager instrument were based on clients' functioning and experiences for the three months prior to the current interview.

In addition to the case manager questionnaire just described, case managers also were asked to rate, on the three-point problem scale described above, the degree to which problems in client's functioning at home, in treatment, at work, or in public contributed to a decision to rehospitalize a client, either through revocation of the conditional release or on a voluntary basis. Researchers administered the instrument developed for this interview-the Reasons for Rehospitalization Questionnaire--within one week after a subject was rehospitalized (Williams \& Bloom, 1989) •

Interviewers assessed current symptomatology of the 54 subjects participating in this study with the mental health status measures Symptom Checklist 90, Revised Version (SCL90-R) (Derogatis, 1992) and the Global Assessment scale (GAS) from the Schedule for Affective Disorders and Schizophrenia--Change (SADS-C) (Endicott, spitzer, Fleiss, \& 
Cohen, 1976). Both of these mental health status instruments restricted responses to a specific period of time--clients' functioning over the past week (last seven days) prior to the current interview.

The SCL-90-R is a 90-item self-report measure of psychological symptom distress developed by L. R. Derogatis and colleagues at the Clinical Psychometrics Research Unit of Johns Hopkins University (Derogatis, 1992). It has been administered to a wide variety of populations--psychiatric (including forensic) patients, cancer and heart patients, students, drug users and alcoholics, and those with sexual disorders (Derogatis, 1985). Each item is rated on a 5point response scale, which ranges from "not at all" to "extremely" bothered by a particular symptom. Nine primary symptom dimensions are derived from the responses. These dimensions are somatization, obsessive-compulsive, interpersonal sensitivity, depression, anxiety, hostility, phobic anxiety, paranoid ideation, and psychoticism. There are also three global indices in the SCL-90-R which provide some overall assessment of a patient's psychopathological status. of these global measures, Derogatis (1992) called the Global severity Index (GSI) the most sensitive indicator of psychological distress and recommended it for situations where a single summary score is desired. It is derived by a simple mathematical procedure of dividing the grand total of the 90 items' 
ratings by 90 . In a factor analytic study of the SCL-90-R, Cyr, McKenna-Foley, and Peacock (1985) stated that this instrument is, psychometrically, "a better measure of general distress than of distinct dimensions of psychopathology" (p. 576), supporting the use of a global index measure over the primary dimension scores. The SCL90-R is well-known for its use in assessing changes over time (National Institute of Mental Health [NIMH], 1986). Reliability (internal consistency and test-retest) coefficients for the nine primary symptom dimensions are quite high, ranging between .77 to .90 (Derogatis, 1992). Criterion-related studies, comparing scores on the SCL-90-R and other instruments (e.g., MMPI clinical scales, Wiggins content scales, Tyron cluster scales, Middlesex Hospital Questionnaire symptom dimensions) as well as studies in which subjects' responses are compared to an analogue version rated by clinicians, have provided mixed results (Derogatis, 1985). Studies conducted to demonstrate construct validity are well documented in the SCL-90-R manual, but remain inconclusive.

Endicott, et al. (1976) developed the Global Assessment scale (GAS) of the SADS-C. Interviewers rate subjects' functioning on a scale ranging from 1-to-100, in which the higher the rating, the better interviewers evaluate the subject's functioning to be. There are 10-point intervals, and examples describing typical subject behavior for each 
interval help interviewers determine the rating. The Appendix in this thesis contains a description of each of these intervals. The authors have reported interrater reliabilities for both inpatients and outpatients ranging from .61 to .91. No test-retest or alternative forms correlations are available. The GAS has been correlated with other measures of overall severity of illness. Results from these comparisons have varied with population, scale, time, treatment interventions and perceived social adequacy ratings. Outpatient scale scores typically range from 31 to 70, and for inpatients the range is generally from 1 to 40 . Scores above 70 are not common for persons undergoing mental health treatment (NIMH, 1986).

\section{PROCEDURE}

This author extracted data used for this thesis from the existing PSRB database belonging to the Department of Psychiatry at oregon Health Sciences University, Portland, oregon. Permission for use of this database was sought from, and granted by, the Principal Investigator of the PSRB research studies--the Chair of the Department of Psychiatry at OHSU. The Human subjects committee at OHSU had reviewed and approved the use of human subjects prior to the beginning of the PSRB interview study which began in 1987. Verbal approval for waiving a review by Portland state University's Human Subjects Committee of this thesis' 
proposal was granted by that Committee's chair, owing to the pre-existing nature of the database used and the lack of subject identifiers on data extracted for this thesis.

This author obtained information about previous data collection, entry, and analysis procedures for the PSRB database from written documentation of procedures, prior publications by the PSRB research team about studies they conducted, and personal discussions with various members of the OHSU research team involved in the PSRB research study efforts. These people included the Principal Investigator, the Project Director, the Database Manager, and Research Assistants.

The data were in several forms: (1) computer data files in R:Base 3.0 and Crunch statistical Package 4.0; computerized printouts of summary reports for frequencies, means, and standard deviations; and (3) raw data. The rest of the Procedure section which follows is a description of the interview procedures undertaken by the researchers in conducting the PSRB interview study between August 1, 1987 and July $31,1989$.

Researchers conducted interviews each month at one of the three treatment programs on a rotational basis, so that subjects were interviewed once every three months, usually at their community mental health setting. Twenty-nine subjects were interviewed during the first rotation (the initial three months). Following this rotation, twenty-five 
new releasees were added to the interview subject schedule during the study period. Interviewers added these new subjects during the next set of interviews that followed their release to the community treatment program. Thus, over the course of two years eight interview rotations--Time 1 through Time $8\left(T_{1}-T_{8}\right)$--were conducted at each treatment program. The total number of subject interviews was 234 , for an average of 29 per rotation.

The number of interviews any individual subject received depended on several factors, including the time he entered the study (when he was conditionally released), how long he remained in the community program, and his willingness or availability to be interviewed at any point in the study. Subjects' interview availability or placement status can be described by several patterns, referred to as subject "movement." Following the initial movement to conditional release, the subjects may have moved to one or more of the following statuses (see Figure 1): discharge from the jurisdiction of the PSRB, rehospitalization (voluntary or via revocation), transfer to another community program not participating in this study, or escape from supervision (AWOL from community placement).

In addition to these potential movement patterns, subjects may have dropped out of the study at any point or refused or were absent for a single interview, but then continued in the study after that. Thus, the total number 


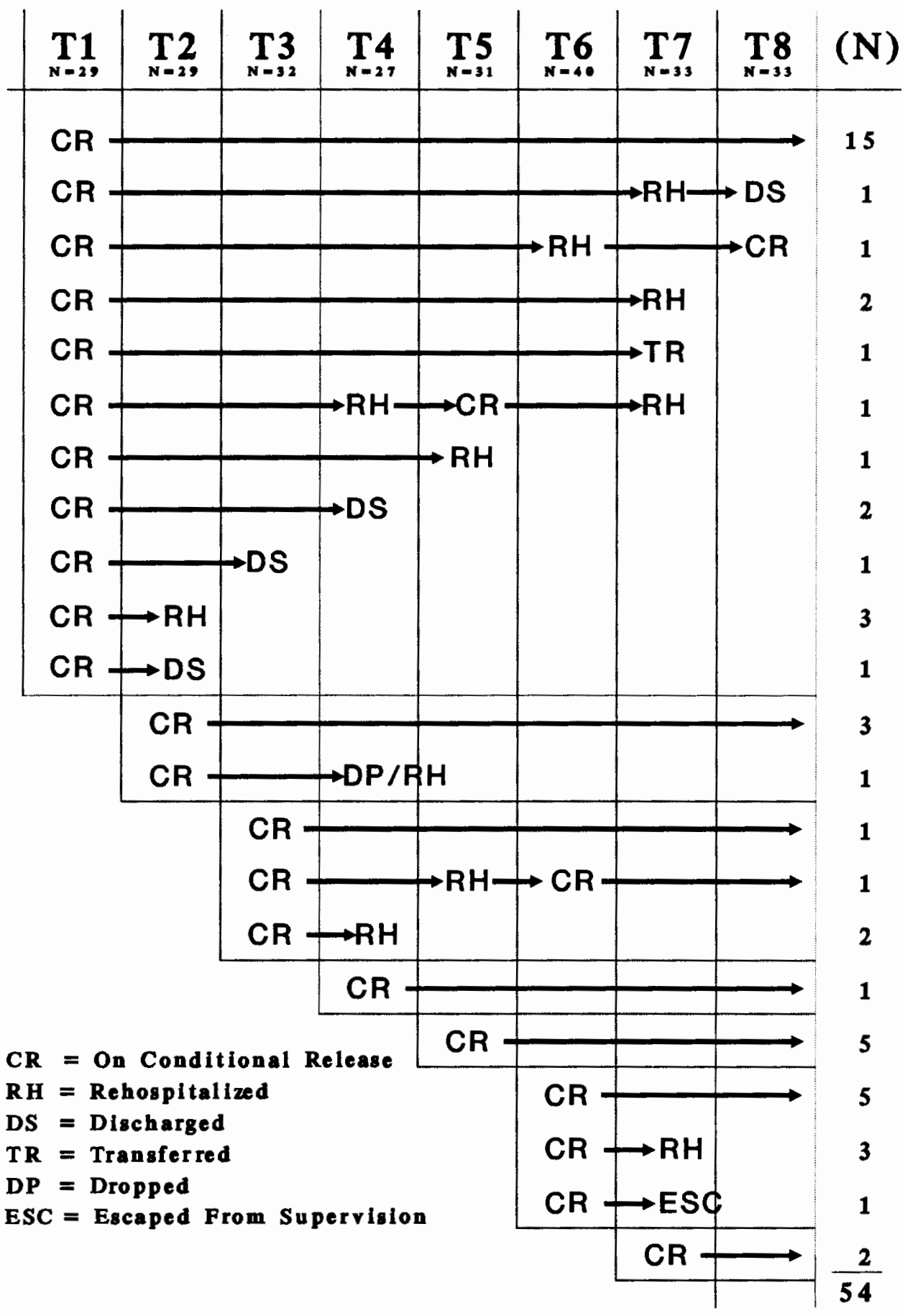

Figure 1. Subject movement patterns during study period. 
of interviews for each subject could differ for a variety of reasons. Only those subjects who already were on release at the time of the first rotation of interviews and remained in the program the entire two years had the potential to be interviewed at all eight times.

Subjects provided client background information (demographics) during the first interview only. GAS measurement began with a client's initial interview and was re-measured with each succeeding client interview. The maximum number of GAS scores possible for a client was, therefore, eight. Fifty-four subjects received GAS ratings at least once during the study period. Eleven subjects received all eight ratings.

PSRB researchers added the SCL-90-R to the instrument schedule in the Time 3 rotation, and never administered it during a client's initial interview, even when a client began participating at $\mathrm{T}_{3}$ or later. Therefore, the maximum number of administrations possible for this instrument was six ( $T_{3}$ through $T_{8}$ ), providing a client was in the study prior to $T_{3}$ and participated in at least one interview after $\mathrm{T}_{2}$. If a client was no longer participating in the study after $\mathrm{T}_{2}$ or only participated in one interview rotation over the entire two-year study period, he never received the SCL90-R. Forty-three clients received the SCL-90-R at least once during the study period, and 13 received this instrument on all possible occasions $\left(\mathrm{T}_{3}-\mathrm{T}_{8}\right)$. 
The 54 subjects of this study were monitored and managed by five case managers, one each at the two smaller settings and three at the largest setting. The case manager interviews, in which case managers were asked about clients' functioning, were administered each rotation for each client in the study. Individual subjects' responses to the SCL-90$\mathrm{R}$ were never discussed with case managers.

For $T_{1}$ through $T_{5}$, a psychologist and one of two research assistants alternately conducted the interviews while the other observed and independently coded responses. Later, interviewers discussed and reconciled any differences in coding. Interrater reliability was high. There was an average difference of seven points for the interviewer-rated GAS scores. Interrater reliability for recording subject responses on the SCL-90-R, client background and case manager questionnaire responses also was high, averaging about 90-95\% agreement between the psychologist and the research assistant conducting or observing the interviews. Therefore, after $T_{5}$ researchers decided, given the high interrater reliability, to have the psychologist conduct the last three interview rotations without a research assistant.

\section{CALCULATIONS}

PSRB researchers had calculated frequencies, means, and standard deviations for most of the case manager and subject variables used in this thesis, using two computer software 
programs--Crunch Statistical Package 4.0 and R:Base 3.0. This author converted SCL-90-R raw scores, which had previously been entered into the database, to T-scores using a computerized scoring program obtained from the clinical Psychometrics Research Unit. The T-scores had a mean of 50 and a standard deviation of 10. This scoring program based subjects' SCL-90-R computerized scoring results on the norm supplied by Derogatis (1992) for male psychiatric outpatients. This author analyzed the interviewer-rated raw scores of the GAS for means and standard deviations using Crunch 4.0 .

A problem with analyzing the mental status outcome measures--the SCL-90-R and GAS--was related to the various patterns of subject movement discussed earlier in this thesis, where subjects began or ended their participation during different interview rotations of the study. The majority of subjects were not study participants throughout the entire study period. $T_{1}$ and $T_{2}$ interviews did not have GSI scores, as the SCL-90-R was added at $T_{3}$. Only 11 subjects had GAS scores for all eight rotations. A similar limitation existed for the GSI, where only 13 subjects had GSI scores for all six rotations in which the SCL-90-R was administered $\left(\mathrm{T}_{3}-\mathrm{T}_{8}\right)$. Given these circumstances, this author did not employ repeated measures analyses of variance, as these numbers of subjects were not adequate for that procedure. 
Instead of repeated measures analyses of variance, this author used a chi squared statistic to measure stability of GSI scores on the individual level, comparing the variances of the individual scores $\left(\mathrm{SD}^{2}{ }_{\mathrm{Ind}}\right)$ to the standard error of measure ( $S D_{\text {Meas }}$ ) for the GSI. This author hand-calculated chi squared observed (subject) scores (estimated test-retest reliability $=0.90)^{1}$ for the 27 subjects who had three or more scores on the GSI. The chi squared distributions were limited to these subjects, as it was felt that two individual scores on this measure would not provide adequate information about stability over time. The null hypothesis stated that variability in subjects' (observed) scores over time was less than or equal to the expected variability for the GSI, based on the standard error of measure for the GSI. Thus,

$$
\begin{aligned}
& \mathrm{H}_{0}=\chi_{\text {obs }}^{2} \leq \chi_{\text {crit }}^{2} \\
& \mathrm{H}_{1}=\chi_{\text {obs }}^{2}>\chi_{\text {crit }}^{2}
\end{aligned}
$$

Chi squared was not used for the GAS scores, as no data are available for a test-retest reliability coefficient for

${ }^{1}$ Test-retest reliability coefficients were not available for the global indices of the SCL-90-R. The testretest reliability coefficients for each of the nine symptom dimensions were provided by Derogatis (1992) in the SCL-90-R Manual and ranged between 0.78 to 0.90 . It was decided to use the highest dimension coefficient--0.90--to estimate GSI test-retest reliability, as the higher the coefficient used to calculate chi squared observed, the more likely to reject the null hypothesis, and to attribute variability in observed scores to events occurring over time. 
this measure. This limitation is likely due to the fact that GAS measurement is based on a client's functioning in several areas--family relations, social, occupational, school, and self-care, as well as psychiatric symptomatology. Fluctuations in one or more of these areas are likely to occur under any circumstances, and effects on mood and functioning are to be expected as a normal course of events. Therefore, test-retest measurements would not be very applicable to this measure.

This author also calculated means and standard deviations for all scores of the nine symptom dimensions and GSI from the SCL-90-R (number of subjects with scores $=43$ ) and for all scores for the GAS (number of subjects with scores $=54)$. A separate recalculation of the mean scores for the GAS and the SCL-90-R scores for $\mathrm{T}_{3}$ through $\mathrm{T}_{8}$ was done for those subjects having scores for all six time periods on both instruments $(\underline{n}=13)$, and for the GAS for $\mathrm{T}_{1}-\mathrm{T}_{8}$ for subjects with scores for all eight interviews. Other separate recalculations of the means were undertaken for the SCL-90-R and GAS scores of subjects who were hospitalized at some point following conditional release during the study period (rehospitalized group), and for subjects who were never hospitalized after their conditional release during the two-year study period (nonhospitalized group). This procedure enabled this author to examine the possibility that an improvement in these scores 
over time was due to the lack of scores for rehospitalized subjects who missed one or more interview rotations. Rehospitalized subjects are assumed to represent the least adjusted subjects, so one could expect poorer mental status scores for them, which would increase SCL-90-R means and decrease GAS means. This author also calculated $\underline{t}$-tests for paired groups of first and last SCL-90-R and GAS scores to assess significance.

As stated earlier, the research team at OHSU had previously calculated frequencies, means, and standard deviations for many of the responses given by case managers and subjects. Summary reports of these analyses were available as part of the existing PSRB database. This author extracted results from these reports for variables relevant to this thesis. 
CHAPTER IV

PRESENTATION AND ANALYSIS OF THE DATA

\section{DEMOGRAPHICS}

Table I summarizes subjects demographics. Subjects' mean age when assigned to the PSRB was 29.8 years $(\underline{S D}=$ 8.6). Mean age at the time of subjects' first interview for this interview study was $33.9(\underline{\mathrm{SD}}=6.4$; range $19-57)$. Forty-three (80\%) subjects were White, six (11\%) Black, two (4\%) Native American, two (4\%) Hispanic, and one (2\%) Asian. The majority of subjects had never been married $(\underline{n}=39$, 72\%), 10 (19\%) were divorced, four (7\%) currently married, and one (2\%) was separated from his spouse. Subjects' educational level was as follows: twenty-four (44\%) subjects had some college experience, and another sixteen (30\%) subjects had either completed high school or the GED. One (2\%) subject had post-high school vocational training. Only five (9\%) subjects had less than 10 years of school. All subjects had been admitted to a psychiatric hospital at least once in their Iives. Table II presents information about such prior hospitalizations, in-state and out-ofstate. 
TABLE I

DEMOGRAPHIC CHARACTERISTICS

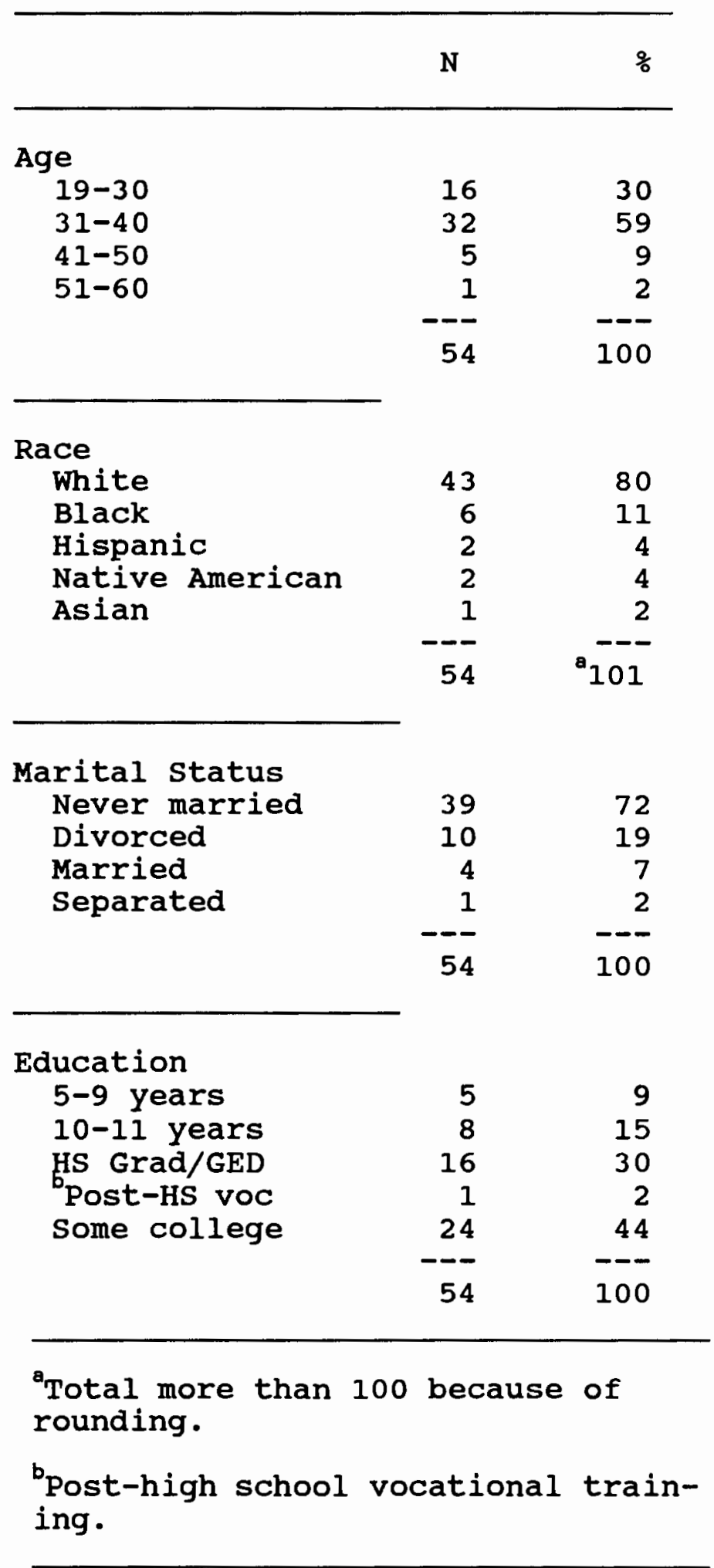


TABLE II

LIFETIME NUMBER OF PSYCHIATRIC

HOSPITALIZATIONS AS REPORTED

BY SUBJECTS

\begin{tabular}{crr}
\hline & N & \% \\
\hline In-state & & \\
$1-3$ times & 26 & 48 \\
$4-10$ times & 18 & 33 \\
$>10$ times & 10 & 19 \\
& $-\frac{-}{-19}$ \\
Out-of-State & 54 & 100 \\
None & 32 & 59 \\
$1-3$ times & 15 & 28 \\
$4-10$ times & 5 & 9 \\
$>10$ times & 2 & 4 \\
& --- & --- \\
& 54 & 100 \\
\hline
\end{tabular}

Table III delineates subjects' primary psychiatric diagnoses as extracted by PSRB researchers from PSRB's client records. Mental health evaluators made these diagnoses around the time the court assigned subjects to the jurisdiction of the PSRB. While not every subject was given a psychosis-related diagnosis at that time, all of the subjects of this study did have such diagnoses in their mental health histories, as required by research criteria. Eighty-two percent $(\underline{n}=37)$ of the 45 subjects for whom the PSRB diagnoses were available were diagnosed with some type of psychosis. Three (8\%) of the 45 subjects had primary diagnoses of personality disorders. 
TABLE III

PRIMARY PSYCHIATRIC DIAGNOSIS AROUND TIME OF ASSIGNMENT TO PSRB

\begin{tabular}{lrr}
\hline \multicolumn{1}{c}{ Diagnosis } & N & \% \\
\hline aPsychosis & 37 & 82 \\
bPersonality Disorder & 3 & 8 \\
CMental Retardation & 2 & 4 \\
Organic Disorder & 2 & 4 \\
Substance Abuse & 1 & 2 \\
Total & --- & --- \\
\hline
\end{tabular}

Note. Nine subjects did not have diagnoses reported.

${ }^{a}$ Some subjects had secondary diagnoses of Personality Disorder and Alcohol Abuse.

bome subjects had secondary diagnoses of Alcohol Abuse and Drug Abuse.

${ }^{c}$ Some subjects had secondary diagnoses of Personality Disorder and Organic Disorder.

The crimes for which subjects were acquitted are identified in Table IV. In meeting research criteria for this interview sample, all of these crimes are felonies. PSRB researchers categorized these crimes by level of seriousness based on crime seriousness classification codes of the Oregon statutes. These categories also may include very serious attempts to commit these crimes. This table depicts subjects' crimes in order of most to least serious. One-third $(\underline{n}=18)$ of the subjects were acquitted for crimes from the two highest seriousness categories-- 
TABLE IV

TYPE OF CRIME FOR WHICH SUBJECT WAS

ACQUITTED IN ORDER OF MOST

TO LEAST SERIOUS

\begin{tabular}{lrr}
\hline \multicolumn{1}{c}{ Crime Category } & N & $\%$ \\
\hline Murder/Manslaughter & 4 & 7 \\
Assault & 14 & 26 \\
Sex-Related Crimes & 2 & 4 \\
Kidnapping & 2 & 4 \\
Robbery & 9 & 17 \\
Arson & 7 & 13 \\
Burglary & 11 & 20 \\
UUV & 3 & 6 \\
Criminal Mischief & 2 & 4 \\
Total & -- & --- \\
& 54 & 101 \\
\hline
\end{tabular}

Note: UUV = Unauthorized Use of Motor Vehicle.

ancludes one attempted murder.

brape, sodomy, etc.

cTotal more than 100 because of rounding.

murder/manslaughter $(\underline{\underline{n}}=4,7 \%)$ and assaults $(\underline{n}=14,26 \%)$. Burglary and robbery were the next most-heavily represented categories, with 11 (20\%) and nine (17\%) subjects, respectively. Seven (13\%) were charged with arson. The remaining four categories had only two or three subjects each in them. Given the level of prior criminality and dangerousness in these subjects, and their acquittal on grounds of insanity, it seems essential that psychological 
functioning be carefully monitored and managed during mandated community treatment.

\section{SCL-90-R RESULTS}

Nine Symptom Dimensions

Means and standard deviations for all scores of the nine symptom dimensions are in Table $v$. All of the means are below 50 for all dimensions, and range from 37.2 to 46.8 . Three dimensions have the highest means for the three groups of all subjects, non-hospitalized subjects, and rehospitalized subjects. These dimensions are

\section{TABLE V}

ALL MEANS FOR 9 SYMPTOM DIMENSIONS OF THE SCL-90-R

\begin{tabular}{lcccccc}
\hline $\begin{array}{l}\text { a Symptom } \\
\text { Dimension }\end{array}$ & $\begin{array}{c}\text { All } \\
\text { Scores }\end{array}$ & SD & $\begin{array}{c}\text { All } \\
\text { NonHosp }\end{array}$ & SD & $\begin{array}{c}\text { All } \\
\text { Rehosp }\end{array}$ & SD \\
\hline & & & & & & \\
Som & 46.8 & 7.9 & 47.5 & 7.7 & 42.7 & 8.0 \\
Obs Comp & 39.7 & 7.5 & 39.9 & 7.3 & 38.5 & 8.3 \\
Intp Senst & 40.1 & 7.8 & 40.4 & 7.6 & 38.2 & 8.8 \\
Dep & 37.2 & 8.8 & 37.2 & 8.8 & 36.7 & 9.0 \\
Anx & 38.6 & 8.2 & 38.9 & 8.2 & 36.3 & 7.8 \\
Hostl & 40.2 & 6.8 & 40.2 & 7.0 & 40.1 & 5.9 \\
Phob Anx & 46.5 & 8.1 & 46.8 & $\mathbf{8 . 1}$ & 44.1 & 8.1 \\
Paran Ideat & 44.2 & 7.6 & 44.5 & 7.7 & 42.2 & 6.9 \\
Psychot & 42.0 & $\mathbf{8 . 3}$ & 42.1 & $\mathbf{8 . 6}$ & 40.9 & 6.4 \\
& & & & & & \\
\hline
\end{tabular}

${ }^{a}$ Som = Somatization; Obs comp = Obsessive Compulsive; Intp Senst = Interpersonal Sensitivity; Dep = Depression; $A n x=A n x i e t y ;$ Hostl = Hostility; Phob $A n x=$ Phobic Anxiety; Paran Ideat $=$ Paranoid Ideation; Psychot $=$ Psychoticism. 
somatization, phobic anxiety, and paranoid ideation, and their means range from 42.2 to 47.5 . Overall means for rehospitalized subjects are lower for all dimensions than those for non-hospitalized subjects.

Comparisons between first and last scores for the 13 subjects with scores for $\mathrm{T}_{3}$ to $\mathrm{T}_{8}$ are displayed in Table VI. These t-test results were not significant except for

\section{TABLE VI}

t-TEST RESULTS FOR THE NINE SYMPTOM DIMENSIONS OF THE SCL-90-R FOR

13 SUBJECTS WITH ALL SCORES FOR $\mathrm{T}_{3}-\mathrm{T}_{8}$

\begin{tabular}{lcc}
\hline \multicolumn{1}{c}{ Symptom Dimension } & ${ }^{a}$ Diff & p-value \\
\hline & & \\
Somatization & 5.6 & .01 \\
Obsessive-Compulsive & 4.0 & .13 \\
Interpers. Sensitivity & 2.5 & .12 \\
Depression & 5.4 & .06 \\
Anxiety & 3.5 & .15 \\
Hostility & 2.5 & .22 \\
Phobic Anxiety & 0.5 & .80 \\
Paranoid Ideation & 0.5 & .89 \\
Psychoticism & 4.6 & .12 \\
\hline Difference between the first and last \\
mean scores.
\end{tabular}

somatization. Results for this dimension were: $\underline{t}=3.0, \underline{d f}$ $=11, \underline{p}=.01$.

GSI

The GSI is reported as $\mathrm{T}$-scores, with $\underline{\mathrm{M}}=50$, and $\underline{\mathrm{SD}}=$ 10. The lower the GSI score, the less symptomatic distress 
reported. GSI scores ranged from 27 to 61 . Table VII depicts all mean and standard deviation scores calculated for the GSI. Subjects reported little symptomatology throughout the study. All of the means were at least one standard deviation below the norm expected for this male psychiatric outpatient sample, except for the group of 13 subjects having GSI and GAS scores for all rotations. In this group, GSI means for all normed scores and first scores were 0.1 and 3.2 points above one standard deviation, respectively. Compared with the expected value of 50 and a p-value of <.01, the mean GSI scores which fall more than one standard deviation below the norm are highly significant.

The overall means for the GSI, based on all scores recorded, was $38.7(\underline{S D}=7.5)$, with scores ranging from 27 to 61. For the non-hospitalized group, GSI scores were available for 35 of the 38 subjects. The mean GSI score for

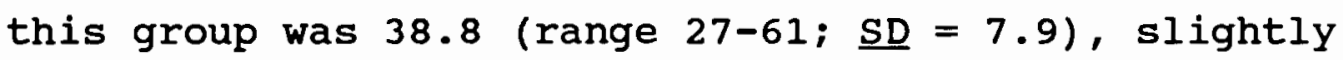
higher, than for the rehospitalized group. GSI scores for the rehospitalized subjects were available for eight of the 16 subjects, and the mean GSI for this group was 36.7 (range $27-57 ; \underline{S D}=7.3)$. For the 13 subjects who had all GSI scores for $\mathrm{T}_{3}$ through $\mathrm{T}_{8}$, representing the most complete and consistent information for the GSI, the overall mean was the highest calculated for this measure for all scores--40.1-with scores ranging between 27 and $43(\underline{S D}=7.6)$. 
TABLE VII

ALL MEANS CALCULATED FOR GSI

\begin{tabular}{cccc}
\hline Subject Group & N & Mean & SD \\
\hline $\begin{array}{c}\text { All Subjects } \\
\text { All scores }\end{array}$ & 43 & 38.7 & 7.5 \\
\cline { 1 - 2 } $\begin{array}{c}\text { Non-Hospitalized } \\
\text { All scores }\end{array}$ & 35 & 38.8 & 7.9 \\
\hline $\begin{array}{c}\text { Rehospitalized } \\
\text { All scores }\end{array}$ & & & \\
\hline $\begin{array}{c}\text { T8 -- all 6 scores } \\
\text { All scores }\end{array}$ & 8 & 36.7 & 7.3 \\
First scores & 13 & & \\
Last scores & 13 & 40.1 & 7.6 \\
& 13 & 36.5 & 9.5 \\
\end{tabular}

GSI means for the $\mathrm{T}_{3}-\mathrm{T}_{8}$ group's first and last interview scores were $43.2(\underline{\mathrm{SD}}=9.5)$ for first scores, and 36.5 ( $\underline{\mathrm{SD}}=$ 6.4) for last scores. Comparing first and last means for this group of subjects, the mean for last scores is lower than the mean for first scores, indicating less reported symptomatic distress at subjects' last interview than at their first interview.

A comparison between first and last means of the $\mathrm{T}_{3}-\mathrm{T}_{8}$ group (subjects with all six scores) reveals a modest decrease ( 6.7 points) in reported distress over time. In order to test for the significance of difference between first $(\underline{M}=43.2)$ and last GSI mean scores $(\underline{M}=36.5)$ of this subject group, this author conducted a paired-group t-test. 
Significant differences over time were indicated. The results of this test are as follows: $\underline{t}=2.44$, df $=12, \underline{p}=$ .031. A paired comparison t-test between non-hospitalized and rehospitalized groups for first and last scores was not undertaken, as only eight rehospitalized subjects had any scores, and the number averaged less than three scores per subject.

The results of the chi squared comparisons for the GSI are reported next. Out of the 27 subjects with more than two scores over the eight interview rotations, for 14 (52\%), variability of scores over time was not significant. For 13 (48\%) of these subjects, variability was significant. At a significance level of .05 , one would expect nearly all subjects' (25.7 out of the 27 in this sample) to have nonsignificant variability. These results show more individual variation than due to chance, which may suggest that for this sample, individual subjects' reported symptomatology does significantly fluctuate over time. There was no difference between the groups of subjects with significant fluctuations and subjects with non-significant variability in terms of the number of subjects rehospitalized--both had two subjects each that were rehospitalized during the study period.

other differences, such as for demographics or other more stable personality variables, were not assessed, as prior research of this nature has produced mixed results, at 
least in part because operational definitions of variables have varied considerably across studies. Differences in such definitions make it difficult to compare or generalize findings to other jurisdictions.

In addition to the above concerns, another caution is warranted in interpreting these chi squared results. Derogatis (1992) did not give a test-retest reliability coefficient for the GSI. The .90 test-retest reliability coefficient used to calculate chi squared observed was estimated from the coefficients for the nine symptom dimensions, as described in footnote number one, and was selected because it minimized accepting a false null hypothesis. If true test-retest reliability for the GSI is actually lower, fewer subjects would have a significant difference in variability of their scores.

\section{GAS RESULTS}

GAS ratings were available for all 54 subjects. Table VIII presents the means and standard deviations calculated for this measure. As stated earlier in this paper, the typical range on the GAS for this population is from 31 to 70 (NIMH, 1986). The participants in this study had GAS scores which ranged from 36 to 84 , and their overall GAS mean was $61.4(\underline{\mathrm{SD}}=10.2)$.

Overall mean GAS scores for all 54 subjects, the nonhospitalized and the rehospitalized groups were very 
TABLE VIII

ALL MEANS CALCULATED FOR GAS

\begin{tabular}{|c|c|c|c|}
\hline Subject Group & $N$ & Mean & $S D$ \\
\hline $\begin{array}{l}\text { All Subjects } \\
\text { All scores }\end{array}$ & 54 & 61.4 & 10.2 \\
\hline $\begin{array}{c}\text { Non-Hospitalized } \\
\text { All scores }\end{array}$ & 38 & 61.5 & 9.6 \\
\hline $\begin{array}{l}\text { Rehospitalized } \\
\text { All scores }\end{array}$ & 16 & 60.8 & 12.8 \\
\hline $\begin{array}{c}\mathrm{T}_{3}-\mathrm{T}_{8}-\text { all } 6 \text { scores } \\
\text { All scores } \\
\text { First scores } \\
\text { Last scores }\end{array}$ & $\begin{array}{l}13 \\
13 \\
13\end{array}$ & $\begin{array}{l}59.8 \\
52.4 \\
63.0\end{array}$ & $\begin{array}{r}9.4 \\
9.7 \\
10.1\end{array}$ \\
\hline $\begin{array}{c}\mathrm{T}_{1}-\mathrm{T}_{8}-- \text { all } 8 \text { scores } \\
\text { All scores } \\
\text { First scores } \\
\text { Last scores }\end{array}$ & $\begin{array}{l}11 \\
11 \\
11\end{array}$ & $\begin{array}{l}59.4 \\
49.5 \\
64.6\end{array}$ & $\begin{array}{r}10.1 \\
10.2 \\
8.8\end{array}$ \\
\hline
\end{tabular}

similar, differing by no more than 2.1 points. GAS means for all scores of the non-hospitalized and rehospitalized groups were $61.5(\underline{\mathrm{SD}}=9.6$; range $38-84)$ and 60.8 ( $\underline{\mathrm{SD}}=$ 12.8; range 36-83), respectively. The calculated mean for the 13 subjects who had all the GAS and GSI scores for $T_{3}$ through $\mathrm{T}_{8}$ (the most complete and consistently measured group for the two mental status measures together) was 59.8 $(\underline{S D}=9.4 ;$ range 38-84). Eleven subjects had all eight scores for $\mathrm{T}_{1}$ to $\mathrm{T}_{8}$. The mean for this group was 59.4 ( $\underline{\mathrm{SD}}=$ 10.1 ; range $38-84$ ). 
To test for significance between for first and last scores for the group of 11 and group of 13 subjects discussed above, this author performed $\underline{t}$-tests for these groups' GAS scores. t-test results for both groups were significant. As stated before, subjects in these groups were never rehospitalized during the study period and therefore are possibly representative of the more adjusted and well-functioning subjects. Findings for these paired comparisons for the 13 subjects from $\mathrm{T}_{3}-\mathrm{T}_{8}$ were the following: $\underline{t}=-3.01, \underline{\mathrm{d}}=12, \underline{\underline{p}}=.011(\underline{\mathrm{M}}=52.4$ for first scores; $\underline{M}=63.0$ for last scores). For the 11 subjects $w i t h$ all scores in all eight rotations, the mean for first scores was 49.5 and for last scores the mean was 64.6 . Results of $\underline{t}$-test comparisons for this group were $\underline{t}=-5.30$, $\underline{\mathrm{df}}=10, \underline{\mathrm{p}}$ $=.0003$. There was a 10.6-point increase from first to last scores for the 13 subject group and a 15.1 point increase in the mean for comparable scores for the 11 subject group.

\section{CASE MANAGERS' REPORTS OF PROBLEMS}

The PSRB Database Manager had previously collapsed data on subjects' overall treatment performance (which included fulfilling expectations of the individualized treatment plan, such as attendance in specific structured day treatment activities or mental health services), mental condition, dangerousness, and compliance in two ways: (1) to reflect the most severe rating of problems reported during 
the study period for each subject, and (2) to report frequencies of each response option. The rating scale, from the least to the most severe rating, was ranked as follows: $1=$ no or only minor problems, 2 = significant problems, and 3 = extreme problems. For the first method of collapsing data, data were recorded for each of these variables as the highest rating given across each subject's interviews. For example, for a subject who had four case manager interviews with the following responses to a variable: $T_{3}=1, T_{4}=2$, $\mathrm{T}_{5}=1$, and $\mathrm{T}_{6}=1$, the highest response given over the four interviews was $2, "$ " ( $\mathrm{T}_{4}$ response) which was then the recorded response for that variable in the database. Narrative interview material provided information about legal contacts or charges and dangerousness.

Case managers reported having contact with subjects on an average of slightly more than once a week. This contact typically involved individual case management and/or individual therapy; in addition, many clients attended day treatment functions where case managers had more opportunity to observe clients' functioning firsthand. Case managers reported relatively few problems with these community-based clients' compliance, mental condition, dangerousness, or legal contacts/charges.

\section{Compliance with Treatment}

A summary of the highest scores ever reported by case managers for individual subjects' overall treatment 
performance was as follows: significant problems were reported as the highest score $4 \%$ of the time, and in $96 \%$ of the interviews, no or only minor problems were the highest score ever reported for overall treatment performance. Case managers never reported extreme problems in overall treatment performance. Extreme problems were also not reported for psychiatric medication compliance. In only one case were significant problems with psychiatric medication compliance reported as the highest rating. No or only minor problems with medication compliance were reported $99 \%$ of the time.

\section{Mental/Emotional condition}

PSRB researchers had collapsed data on case managers' reports of subjects' mental/emotional condition differently than for the above variables, tabulating the frequencies of responses for each of the three severity rating options. Once again, case managers reported few problems for the majority of subjects, although more problems were reported for this variable than for the compliance variables previously described. Out of 233 interviews with reports on mental/emotional condition, in 192 (82\%) interviews, case managers reported no or only minor problems with subjects' mental/emotional condition. Significant problems with mental/emotional condition were reported in 39 (17\%) of case manager interviews. Case managers reported extreme problems 
with mental/emotional condition in only 2 (1\%) of interviews.

\section{Dangerousness}

Table IX displays the types of dangerousness reported by case managers. Over the course of the two years and

TABLE IX

FREQUENCY OF INCIDENCES OF

DANGEROUSNESS REPORTED

BY CASE MANAGERS

\begin{tabular}{lc}
\hline $\begin{array}{c}\text { Type of } \\
\text { Dangerousness }\end{array}$ & Freq. \\
\hline Hostility, delusions, & 7 \\
or anger & 5 \\
Behaviors, displays & 2 \\
Family conflict & 3 \\
Assault & 1 \\
Property Damage & $--\frac{1}{}$ \\
& 18 \\
\hline
\end{tabular}

233 interviews, case managers reported, in 18 (8\%)

interviews, 17 incidences of significant, and one of extreme, dangerousness, in a total of seven different subjects. In the one report of extreme dangerousness, the case manager was reporting on the danger for potential assaultive behavior by a subject towards one family member; the subject actually never was assaultive. According to the case manager, there was an equal amount of concern regarding the potential for dangerous assault from this family member 
towards the subject himself.

None of the seven subjects for whom dangerousness was significant or extreme required rehospitalization during the study period, and five of these seven subjects participated in interviews the entire eight rotations, indicating these subjects were among the most manageable during the study period.

\section{Legal Contacts/Charges}

Another way of determining how problematic these insanity acquittees are for society is to study their reoffenses while on conditional release. Case managers reported eight incidences of legal contacts or charges for seven subjects (only one of whom was among the seven with reports of dangerousness). The two charges reported were for relatively minor offenses. The most serious charge-breaking and entering--involved a subject breaking into a former friend's home to retrieve an abandoned possession. The other incident involved the subject being charged for shoplifting. Neither of these offenses were as serious as those which resulted in the subjects' assignment to the PSRB.

other legal contacts not involving charges were dealt with in the community setting. In the two cases of family conflicts, police were called to the subjects' homes by family members, but no charges were filed. The remaining four legal contacts were for traffic offenses. None of the 
seven subjects with legal problems were rehospitalized at the time of these incidents, although two were rehospitalized at some later point in the study period.

From the above data, legal problems and problems with dangerousness for these interview subjects were relatively few and did not directly result in removal of the subjects from the community. This may indicate that extreme dangerousness and legal difficulties were averted by early community intervention whenever possible.

\section{Reasons for Rehospitalization}

Sixteen (30\%) of the 54 subjects were rehospitalized following conditional release during the two-year study period. (Although this figure is similar to those given in some other studies for similar populations--see Goldmeier, et al., 1980 and Cavanaugh \& Wasyliw, 1988a,b, for example-measurement criteria of rehospitalizations differ between studies, making it difficult to draw valid comparisons (Nicholson, Norwood, \& Enyart, 1991)). Problems which led to rehospitalization were usually not reported during regular interview rotations, as they often occurred during the three months between rotations. Summary data from the Reasons for Rehospitalization Questionnaire, which researchers administered to case managers within one week after rehospitalization of a client, were available in the PSRB database.

In the Reasons for Rehospitalization Questionnaire, 
case managers were asked what was (were) the primary reason(s) for the decision to rehospitalize a client. Case managers most frequently cited the following as primary reasons for rehospitalization (some subjects had multiple reasons given) ${ }^{2}$ (a) alcohol or illicit drug use (six subjects; $38 \%$ ) which is a violation of the conditional release contract; (b) not following the treatment plan expectations (excluding substance use) in terms of residential, self-care, or occupational demands, or unexcused absences from supervision ( mental decompensation (three subjects; 19\%); (d) some type of dangerousness (three subjects; 19\%); (e) refusing medications (two subjects; $13 \%$ ); and (f) driving under the influence of intoxicants (one subject; 6\%). Of the above six categories, four are mostly related to subjects' compliance $(a, b, e$, and $f)$, and the other two are related to the criteria upon which the insanity defense rests-mental illness and dangerousness (c and d), although there is overlap between these divisions.

For three subjects, case managers gave, as the sole primary reason for rehospitalization, dangerousness (one subject) or mental decompensation (two subjects). The remaining three subjects from these two categories had compliance related reasons in addition to dangerousness or

${ }^{2}$ Percentages given in this paragraph are based on the percent of rehospitalized only subjects. 
mental decompensation given for their rehospitalizations. Thus, only three (19\%) of rehospitalized subjects (5.5\% of the entire study sample) were primarily rehospitalized solely for mental decompensation or dangerousness. Another three (5.5\%) of the 54 study participants were primarily rehospitalized for dangerousness or mental decompensation and additional reasons for non-compliance. 


\section{CHAPTER V}

\section{DISCUSSION AND RECOMMENDATIONS}

\section{SUMMARY OF FINDINGS AND CONCLUSIONS}

This thesis has examined the experiences of a sample of male insanity acquittees with histories of serious mental disorders and felony offenses, who were on conditional release to mandated treatment programs in oregon between August 1, 1987 and July 31, 1989. A particular interest of this paper was to describe the ability of community treatment programs to manage and monitor clients' psychiatric symptomatology .

As noted in Chapter I, the majority of insanity acquittees have diagnoses of some type of psychosis. One difficulty with providing psychiatric diagnoses in research studies is that subjects with mental health treatment histories often have received diverse diagnoses from different mental health clinicians and settings. Despite differences in how diagnoses are defined for research studies on insanity acquittees, researchers across studies appear to agree that the majority of insanity acquittees carry a diagnosis of psychosis. The PSRB researchers of this interview study limited their sample to individuals for whom at least half of their past psychiatric hospital 
diagnoses were some type of psychosis. The majority of these subjects also were diagnosed as psychotic around the time they were assigned to the PSRB (see Table III). Therefore, it is likely that the insanity acquittees who comprised this study's sample represented diagnostically the majority of insanity acquittees as reported by other researchers, even though other studies may have used dissimilar diagnostic criteria.

The crimes for which the subjects of this interview study successfully pled insanity were all felonies. This met PSRB researchers' criterion for a subject sample which represented those with a history of the most serious types of criminality. Such individuals would likely be considered by the public as the most potentially dangerous, despite the fact that research findings on predicting dangerousness from past criminality do not fully support this view, as discussed in Chapter I. However, given this prevalent public view, concerns about having potentially dangerous individuals in the community were addressed by this sample of individuals.

The results from analyses of the two mental status measures--the Global symptom Index (GSI) from the SCL-90-R and the Global Assessment Scale (GAS) from the SADS-C-indicated less reported distress from symptomatology and better overall functioning than expected for psychiatric outpatients such as the 54 subjects who participated in this 
study. The GSI scores are highly statistically significant when compared with the expected value of 50 and p-value < .01 . Given these subjects' history of psychosis and psychiatric treatment, as well as their criminal behaviors, interviewers' ratings of subjects' global functioning and subjects' self-ratings of symptomatology seems quite impressive.

Comparisons between non-hospitalized and rehospitalized subjects found only slight differences in the means for both the GSI and the GAS. t-tests for significance between these groups were not done because of small sample size. This author anticipated that rehospitalized subjects would demonstrate more symptomatic distress than non-hospitalized subjects, yet GSI results did not support this. Several factors might account for this finding. Subjects who were rehospitalized may have consciously denied symptomatology out of fear of reprisal (i.e., revocation), or they may have been the group most lacking in insight into their mental condition, which could have resulted in underreporting of symptomatology during interviews and could have contributed to their greater instability on conditional release. Derogatis (1992), who developed the SCL-90-R, stated some of these same concerns. He suggested a subject's inability to accurately assess symptoms and behaviors, or response bias due to the effects of social desirability, could be possible weaknesses of the SCL-90-R. Perhaps, however, subjects 
reported symptomatology accurately, in which case they may not ever have experienced distressful symptoms or else distress arose at times not measured by the interviews (the SCL-90-R limits responses to distress over the past week). It is possible that there were combinations of these factors operating in this group of subjects that could account for the lack of reported distress. Given the low number of scores on which the analyses were based for the rehospitalized group (22 scores compared to 139 scores for the non-hospitalized), as well as the lack of consistency of when subjects were interviewed and the reasons why they ended their participation, it is difficult to draw conclusions from these results.

This author was able to conduct tests for significance between first and last scores of the two subject groups with the most completely and consistently measured scores. These groups were (1) subjects with GSI and GAS scores for all interviews in $\mathrm{T}_{3}$ to $\mathrm{T}_{8}$ and (2) those who had GAS scores for all eight interview rotations. None of the subjects in these subsamples were rehospitalized during the study period. For both the GSI and GAS, there were significant differences in first and last scores, which indicated less reported symptomatic distress and better overall functioning at the end of 18 to 24 months of closely monitored mandated community treatment. These two subsamples were more homogeneous than the non-hospitalized/rehospitalized 
subsample groupings in the following ways: all the subjects in the former subsamples (1) maintained the status of conditional release throughout the study period, participated in all of the interviews, and (3) were never rehospitalized. Some of the subjects in both of the latter subsamples (non-hospitalized or rehospitalized) were conditionally released, discharged, transferred, rehospitalized and then re-released, AWOL, or dropped out at different points in the study period.

All of the nine symptom dimensions measured by the SCL90-R had means lower than the expected norm of 50 . Only one dimension--somatization--was highly significant for the difference between first and last scores of the most consistently measured group of subjects over an 18-month period. However, the depression dimension approached significance $(\underline{p}=.06)$. All of the other dimensions demonstrated an improvement, although also not statistically significant, over the 18 to 24 months. It is not known what factors influenced the change in somatization.

Fluctuations in the degree of symptomatic distress reported by 27 subjects with three or more scores for the SCL-90-R during $\mathrm{T}_{3}-\mathrm{T}_{8}$ were significant for the chi squared analysis. The reasons for the fluctuations in this subsample are not clear, however. Derogatis (1992) stated that, in measuring stability in psychopathological syndromes one has to take into account that these syndromes are 
composed of stable personality traits like intelligence, and fluctuating states such as mood. The test-retest reliability scores Derogatis provided for the SCL-90-R symptom dimensions were based on tests given one week apart, a period of time that, according to Derogatis, would involve little variation in psychological states, indicating few effects from this factor on the measurement reliability coefficients. Therefore, variation in subjects' scores over longer periods of time that is significantly different from the standard error of measure could be attributed partly to psychological state fluctuations.

Applying the above analysis to this study, some of the significant changes in GSI scores over the two-year study period for these 27 subjects could be ascribed to normal fluctuations in psychological states. Yet it is unlikely that this accounts for all of the fluctuation. There were differences in the location and treatment program for these subjects (they were from three different programs each in different counties), as well as different times at which subjects began or left the study. Given the small size of this subsample, it was difficult to assess factors related to programmatic differences, or time-related factors that could have contributed to fluctuations in symptomatology ratings. Variables such as age, number of prior hospitalizations, etc. were not correlated for predictability of recidivism, not only because of the small 
subsample sizes, but also because non-uniform variable definitions and mixed results from past studies have led researchers to question the value of such correlations. This author agrees with the conclusions of researchers mentioned earlier (see p. 15), that research which focuses on evaluating variables such as those associated with supervision strategies, social and economic services, problems with substance abuse, and specific reasons for rehospitalization would contribute more to understanding and developing successful treatment interventions than attempts to make uniform previously-reported, non-generalizable data.

Another concern in interpreting the results of the chi squared analysis involved the use of a high estimated reliability coefficient (.90) for the GSI, which minimized accepting a false null hypothesis (see footnote number one). If true test-retest reliability for the GSI is actually lower, fewer subjects would have a significant difference in variability in their scores. This author recalculated chi squared observed using the lowest, rather than the highest, test-retest reliability coefficient of the nine SCL-90-R symptom dimensions, .78 . Only two subjects had significant variability for this recalculation, which is slightly higher than predicted, although in the expected range $(\underline{p}=.05)$. This second result could raise some question about the reliability of the GSI for measuring changes over time in this group of subjects. However, given the fact that chi 
squared was indiscriminantly measured for all subjects with three or more scores and that time periods for when scores were measured and the movement patterns of these subjects differed, it is difficult to separate out possible effects of the research design on the chi squared distribution results. More research in this area is needed. As can be seen from the findings, the means for overall scores of the GAS for all subjects, non-hospitalized subjects, and rehospitalized subjects fall into the lower end of the 61-70 interval, which indicates "some mild symptoms" or "some difficulty in several areas of functioning...but generally functioning pretty well, has some meaningful interpersonal relationships and most untrained people would not consider him 'sick'." (See Appendix for actual definition.). The statistically significant difference in first scores and last scores for the 11- and 13-subject subsamples (with all scores for all eight rotations and all scores for the last six rotations) represented a symptomatic change from serious or moderate symptoms (41-50 and 51-60 intervals) to some mild symptoms (61-70 interval). Global functioning improved from "serious... impairment in functioning" or "generally functioning with some difficulty", to "some difficulty in several areas...but generally functioning pretty well." Given their history of psychosis and psychiatric treatment, as well as their criminal behaviors, interviewers' ratings of subjects' global functioning seem quite impressive. 
Case managers' reports of subjects' compliance and adjustment were mostly favorable. Few problems were reported for compliance with treatment. of those problems mentioned, most were rated as only minor or significant. Very few were rated as extremely problematic. In terms of mental status, case managers reported more problems in subjects' mental/emotional condition than in compliancerelated areas. It does not seem surprising that for this variable there are more reports of significant and extreme problems than for compliance variables. Given the mental health histories of these clients, as well as the inability to control completely the mental or emotional condition even in clients who are most compliant with their mental health treatment regimes, it seems reasonable to expect that some problems would occur. The fact that case managers reported extreme problems in subjects' mental or emotional condition only two times over the entire study period seems to indicate successful management of a commonly problematic area .

Dangerousness and contacts with legal authorities also were not highly problematic for these subjects, according to case managers. For those subjects for whom dangerousness or legal contacts/charges were a reported problem, case managers were apparently able to contain and/or defuse the situations within the community setting, without resorting to rehospitalizing these subjects. Such successful 
intervention speaks well of the ability of these mandated treatment programs to successfully deal with dangerousness and legal difficulties in clients with histories of serious dangerousness and criminality during mental decompensation. These results also demonstrated appropriate judgment by case managers and the PSRB to not rehospitalize a client unnecessarily or too quickly when signs of dangerousness or legal difficulties appeared. A balanced response of rehabilitating clients using the least restrictive treatment options while also maintaining public safety was apparently operating successfully in these cases. The lack of extreme ratings may also indicate that more extreme dangerousness and legal difficulties were averted by early community intervention and successful management of psychiatric symptomatology.

\section{Substance Use}

A major area of concern in managing these acquittees appears to be that of alcohol and illicit drug use. Refraining from all use of alcohol and/or drugs is a specific condition of all subjects' conditional release plans, as use of even small amounts of these substances seems to be highly associated with serious mental decompensation in many people with chronic mental illnesses. This issue is particularly important for forensic patients who have histories of dangerous behaviors when mentally decompensated (Silver \& Tellefsen, 1991). Problems with 
substance use accounted for the primary reason to rehospitalize six (38\% of all rehospitalized) subjects. Case managers clearly associated additional primary reasons (in addition to substance use) given for rehospitalization of these six subjects, to subjects' use of substances--with one exception. For this one subject, the case manager would only raise the suspicion that substance use was related to the subject's non-compliant behaviors.

From the above data, it appears that substance use was considered enough of a concern to rehospitalize clients, even when mental decompensation or dangerousness was not a serious accompanying problem for them (five subjects). It should also be noted that all subjects whose primary reason for rehospitalization included substance use also received Disulfiram (Antabuse) and/or urinalysis monitoring during their conditional release. These added means to discourage and monitor substance use in acquittees also may have helped to decrease the potential for serious problems of dangerousness and mental deterioration related to substance use by these clients.

One further observation regarding substance use in these subjects bears mentioning. In regular case manager interviews, case managers reported a total of 23 treatment plan violations by 13 subjects over the two-year study period. Sixty-five percent (15 violations) of the violations committed by ten (83\%) of the 13 subjects for 
whom violations were reported, were for substance use. only three of the 13 subjects reported to have violated their treatment plan were ever rehospitalized during the study period. These three were among the ten subjects reported to have violated their treatment plan by the use of alcohol or drugs.

From this case manager information it appears that issues of compliance were often an important focus for managing conditionally-released insanity acquittees, perhaps as much or more than problems related to mental decompensation or dangerousness not associated with treatment compliance. The relatively small amount of reported concerns with dangerousness or mental decompensation may be due, in large measure, to the willingness of case managers and the PSRB to rehospitalize these clients for non-compliant behaviors (refusing medications; substance use; not complying with residential, self-care, occupational, or supervision expectations) that may potentially be indicative of increasing dangerousness or mental decompensation and/or have the potential to seriously weaken the monitoring and management of these acquittees. This type of response to serious problems with compliance may strengthen the structure of the mandated community treatment program by ensuring that those most directly involved with supervising insanity acquittees in the community (i.e., case managers, day treatment staff, 
residential caretakers, employers, family) are regarded as an important part of the monitoring system. Since conditionally-released insanity acquittees' adjustment to community life involved their ability to function in several areas, it seems important that the Board displayed knowledge of clients' functioning in those areas.

There appears to be considerable support from this study for the contention that insanity acquittees who are conditionally released to the community can be monitored and managed successfully under well supervised mandated treatment. In particular, the ability to contain these clients' potentially dangerous psychiatric symptomatology seems to be well-demonstrated, given the few reports of problems in this area.

\section{LIMITATIONS OF THE STUDY}

Several features of this interview study limited analysis, interpretation, and generalizability of the findings. One problem with interpretation was suggested several times in this thesis--that of various potential movement patterns for subjects during the two-year study period. Subjects entered and exited the study at different times and for different reasons, making it difficult to control for subject and subsample variation. Another factor which limited the types of analyses which could be conducted was the small numbers of subjects available for subsampling, 
particularly for the rehospitalized subjects.

The study sample was all male, therefore restricting generalizability to that gender. Also, this study did not include a control group, thus further limiting the usefulness of the obtained results. A possible problem with interpreting the results of the SCL-90-R is that a paperpencil test such as this may be vulnerable to response bias. Generalizability also is limited by the insanity defense statutes for these subjects' jurisdiction. Oregon's statutes state that "a person is guilty except for insanity if, as a result of mental disease or defect at the time of engaging in criminal conduct, the person lacks substantial capacity either to appreciate the criminality of the conduct or to conform the conduct to the requirements of law" (Oregon Revised statutes, § 161.319 (1), 1990). This statute allows for the volition prong of the defense--the inability to conform one's conduct to the legal requirements, even when one knows the action is wrong. oregon's statute is similar to the Durham ruling (see Chapter I) and the American Law Institute' $\mathrm{s}^{3}$ recommendation for the insanity defense. However, some insanity defense statutes for other jurisdictions omit the volition prong. The findings presented in this thesis may not be valid for

${ }^{3}$ The ALI is a committee of legal experts which makes recommendations for model legislation in numerous areas of law. 
jurisdictions with different statutes, as insanity acquittees may vary as a result of such dissimilarity.

\section{RECOMMENDATIONS FOR FURTHER RESEARCH}

Research which involves larger samples, control or comparison groups, and more control for consistency of community tenure, would allow for statistical analyses not possible for this study sample. Studies which explore community-based clients' treatment conditions and structure, social and economic services, interpersonal relationships, use of time, and substance use, as well as specific reasons for rehospitalization, may provide relevant information about elements in community treatment programs that enhance successful conditional release of insanity acquittees. Findings from this study about the prevalence of substance use indicate the need for more research in this area, including exploring preventive measures, such as substance abuse counseling and/or education of acquittees as to the effects of substance use on their mental health. Measures such as these taken prior to release from the hospital may be effective in preventing post-release substance use problems. In addition, attention should be given to the training of treatment providers in the signs or symptoms of substance abuse, in order to better detect problems in this area.

More frequent measurement, perhaps once a month, of 
psychiatric symptomatology and functioning using mental status measures such as the SCL-90-R and the SADS-C maY reveal changes in mental condition that are predictors of mental decompensation. In the present study, the lapse of three months between interviews may have decreased the ability to detect these changes. Such predictors could signal the need for interventions that might avert, or lessen the seriousness of, psychological problems. The development of reliable mental status predictors using measures of symptomatology and global functioning possibly could be used in determining the readiness of hospitalized acquittees for conditional release.

Interviews with insanity acquittees' treatment providers about their monitoring and decision-making processes may prove instructive. In particular, information related to how treatment providers determine appropriate, least restrictive, and successful intervention responses to clients' non-compliance, dangerousness, and/or mental decompensation, could increase knowledge about what factors are involved in balancing rehabilitation with public safety concerns. 
REFERENCES

Aadland, R.L. \& Schag, D.S. (1984). The assessment of continued threat to the community in a mentally ill offender program. Journal of Criminal Justice, 12, 8186 .

Avison, W.R. \& Speechley, K.N. (1987). The discharged psychiatric patient: A review of social, socialpsychological, and psychiatric correlates of outcome, American Journal of Psychiatry, 144, 10-18.

Baker, F. \& Douglas, C. (1990). Housing environments and community adjustment of severely mentally ill persons. Community Mental Health Journal, 26, 497-505.

Bloom, J.L. \& Bloom, J.D. (1981). Disposition of insanity defense cases in Oregon. American Association of Psychiatry and Law Bulletin, 9, 93-99.

Bloom, J.D., Bradford, J.M., \& Kofoed, I. (1988). An overview of psychiatric treatment approaches to three offender groups. Hospital and Community Psychiatry, 39, 151-158.

Bloom, J.D., Rogers, J.L., \& Manson, S.M. (1982). After Oregon's insanity defense: A comparison of conditional release and hospitalization. International Journal of Law and Psychiatry, 5, p. 391-402.

Bloom, J.D., Williams, M.H., \& Bigelow, D.A. (1991). Monitored conditional release of persons found not guilty by reason of insanity. American Journal of Psychiatry, 148, 444-448.

Bloom, J.D., Williams, M.H., Rogers, J.L., \& Barbur, P. (1986). Evaluation and treatment of insanity acquittees in the community. Bulletin of the American Academy of Psychiatry and the Law, 14, 221-244.

Bursten, B. (1986). Post hospital mandatory outpatient treatment. American Journal of Psychiatry, 143, 12551258 .

Caplan, L. (1984). The insanity defense and the trial of John $W$. Hinckley, Jr. Boston: David R. Godine, Publisher, Inc. 
Cavanaugh, J.L. \& Wasyliw, O.E. (1985a). Adjustment of the not guilty by reason of insanity (NGRI) outpatient: An initial report. Journal of Forensic Sciences, $30,24-$ 30.

Cavanaugh, J.L. \& Wasyliw, O.E. (1985b). Treating the not guilty by reason of insanity outpatient: A two-year study. Bulletin of the American Academy of Psychiatry and the Law, 13, 407-415.

Cohen, M.I. Spodak, M.K., Silver, S.B., \& Williams, K. (1988). Predicting outcome of insanity acquittees released to the community. Behavioral sciences \& the

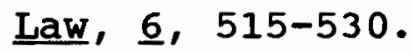

Cyr, J.J., McKenna-Foley, J.M., \& Peacock, E. (1985). Factor structure of the SCL-90-R: Is there one? Journal of Personality Assessment, 49, 571-578.

Derogatis, L.R. (1992). SCL-90-R administration, scoring \& procedures manual-II. Towson, MD: Clinical Psychometric Research.

Derogatis, L.R. (1985) . SCL-90-R. In D.J. Keyser \& R.C. Sweetland (Eds.), Test critiques (pp.583-594). Kansas city, Mo: Test Corporation of America.

Eisner, H.R. (1989). Returning the not guilty by reason of insanity to the community: A new scale to determine readiness. Bulletin of the American Academy of Psychiatry and Law, 17, 401-413.

Endicott, J., Spitzer, R.L., Fleiss, J.L., \& Cohen, J. (1976). The Global Assessment Scale: A procedure for measuring the overall severity of psychiatric disturbance. Archives of General Psychiatry, 33, 766771 .

Golding, S.L., Eaves, D., \& Kowaz, A.M. (1989). The assessment, treatment and community outcome of insanity acquittees: Forensic history and response to treatment. International Journal of Law and Psychiatry, 12, 149179.

Goldmeier, J., White, E.V., Ulrich, C., \& Klein, G.A. (1980). Community intervention with the mentally ill offender: A residential program. Bulletin of the American Academy for Psychiatry and the Law, $8,72-82$.

Harry, B. \& Steadman, H.J. (1988) . Arrest rates of patients treated at a community mental health center. Hospital and Community Psychiatry, 39, 862-866. 
Kumjukrishnan, R. \& Bradford, J.M.W. (1988). Schizophrenia and major affective disorder: Forensic psychiatric issues. Canadian Journal of Psychiatry, 33, 723-733.

Lamb, H.R., Weinberger, L.E., \& Gross, B.H. (1988a). Court-mandated community outpatient treatment for persons found not guilty by reason of insanity: A fiveyear follow-up. American Journal of Psychiatry, 145, 450-456.

Lamb, H.R., Weinberger, L.E., \& Gross, B.H. (1988b) . Court-mandated outpatient treatment for insanity acquittees: clinical philosophy and implementation. Hospital and Community Psychiatry, 39, 1080-1084.

Leong, G.B., Silva, J.A., \& Weinstock, R. (1991). Dangerous mentally disordered criminals: Unresolvable societal fear? Journal of Forensic Sciences, 36, 210218 .

Morgan, D.W., McCullough, T.M., Jenkins, P.L., \& White, W.M. (1988). Guilty but mentally ill: The South Carolina experience. Bulletin of the American Academy of Psychiatry and the Law, 16, 41-48.

National Institute of Mental Health. (1986). Assessing mental health treatment outcome measurement techniques (DHHS Publication No. ADM 86-1301). Washington, D.C.: U.S. Government Printing office.

Nelson, S.H. \& Berger, V.F. (1988). Current issues in state mental health forensic programs. Bulletin of the American Academy of Psychiatry and the Law, 16, 67-75.

Nicholson, R.A., Norwood, S., \& Enyart, C. (1991). Characteristics and outcomes of insanity acquittees in oklahoma. Behavioral Sciences and the Law, 9, 487-500.

Phillips, M.R., Wolf, A.S., \& Coons, D.J. (1988). Psychiatry and the criminal justice system: Testing the myths. American Journal of Psychiatry, 145, 605-610.

Prins, H. (1990). Some observations of the supervision of dangerous offender patients. British Journal of Psychiatry, 156, 157-162.

Quinsey, V.L. (1988). Assessments of the treatability of forensic patients. Behavioral Sciences \& the Law, $\underline{6}$, 443-452. 
Rogers, J.L. \& Bloom, J.D. (1985). The insanity sentence: oregon's psychiatric security review board. Behavioral Sciences \& the Law, $3,69-84$.

Rogers, J.L., Sack, W.H., Bloom, J.D., \& Manson, S.M. (1983). Women in oregon's insanity defense. The Journal of Psychiatry and the Law, 11, 515-532.

Rose, S.M. \& Black, B.L. (1985). Advocacy and empowerment: Mental health care in the community. Boston: Routledge \& Kegan Paul.

Schutte, N.S., Malouff, J.M., Lucore, P., \& Shern, D. (1988). Incompetency and insanity: Feasibility of community evaluation and treatment, Community Mental Health Journal, 24, 143-150.

Seling, M.J. \& Johnson, G.W. (1990). A bridge to the community for extended-care state hospital patients. Hospital and Community Psychiatry, 41, 180-183.

Silver, S.B. \& Tellefsen, C. (1991). Administrative issues in the follow-up treatment of insanity acquittees. The Journal of Mental Health Administration, 18, 242-252.

Spodak, M.K., Silver, S.B., \& Wright, C.U. (1984). Criminality of discharged insanity acquittees: Fifteen year experience in Maryland reviewed, Bulletin of the American Academy of Psychiatry and the Law, 12, 373382 .

Steadman, H.J. (1985). Insanity defense research and treatment of insanity acquittees. Behavioral sciences \& the Law, $3,37-48$.

Williams, M.H. \& Bloom, J.D. (1989). Mental health services research with forensic populations. In J.D. Bloom (Ed.), New directions for mental health services: State-University collaboration: The oregon experience (pp. 83-95). San Francisco: Jossey-Bass, Inc.

Zonana, H.V., Wells, J.A., Getz, M.A., \& Buchanan, J. (1990). Part I: The NGRI registry: Initial analysis of data collected on connecticut insanity acquittees. Bulletin of the American Academy of Psychiatry and the Law, 18, 115-128. 


\section{APPENDIX}

GLOBAL ASSESSMENT SCALE

91-100 Superior functioning in a wide range of activities, life's problems never seem to get out of hand, is sought out by others because of his warmth and integrity. No symptoms.

81-90 Good functioning in all areas, many interests, socially effective, generally satisfied with life. There may or may not be transient symptoms and "everyday" worries that only occasionally get out of hand.

71-80 No more than slight impairment in functioning, varying degrees of "everyday" worries and problems that sometimes get out of hand. Minimal symptoms may or may not be present.

61-70 Some mild symptoms (eg., depressive mood and mild insomnia) OR some difficulty in several areas of functioning, but generally functioning pretty well, has some meaningful interpersonal relationships and most untrained people would not consider him "sick."

51-60 Moderate symptoms oR generally functioning with some difficulty (eg., few friends and flat affect, depressed mood and pathological self-doubt, euphoric mood and pressure of speech, moderately severe antisocial behavior).

41-50 Any serious symptomatology or impairment in functioning that most clinicians would think obviously requires treatment or attention (eg., suicidal preoccupation or gesture, severe obsessional rituals, frequent anxiety attacks, serious antisocial behavior, compulsive drinking, mild but definite manic syndrome). 


\author{
APPENDIX \\ GLOBAL ASSESSMENT SCALE \\ (continued)
}

31-40 Major impairment in several areas, such as work, family relations, judgment, thinking or mood (eg., depressed woman avoids friends, neglects family, unable to do housework), OR some impairment in reality testing or communication (eg., speech is at times obscure, illogical, or irrelevant), OR single suicide attempt.

21-30 Unable to function in almost all areas (eg., stays in bed all day) OR behavior is considerably influenced by either delusions or hallucinations OR serious impairment in communication (eg., sometimes incoherent or unresponsive) or judgment (eg., acts grossly inappropriately).

11-20 Needs some supervision to prevent hurting self or others, or to maintain minimal personal hygiene (eg., repeated suicide attempts, frequently violent, manic excitement, smears feces) OR gross impairment in communication (eg., largely incoherent or mute).

1-10 Needs constant supervision for several days to prevent hurting self or others (eg., requires an intensive care unit with special observation by staff), makes no attempt to maintain minimal personal hygiene or serious suicide act with clear intent and expectation of death. 